

\title{
Estrategias de gestión ambiental frente al desarrollo minero-extractivista en el municipio de Quinchía (Risaralda) $)^{\S}$
}

\author{
Por Yuliana Salazar Duque*
}

Resumen: Este artículo tiene como propósito analizar las principales estrategias de gestión ambiental implementadas en el municipio de Quinchía, Risaralda, en especial en los corregimientos de Naranjal e Irra, frente al desarrollo minero extractivista en el siglo XXI.

Para tal fin, en primer lugar, se realizó un estado del arte sobre el desarrollo minero extractivista en el contexto nacional, departamental y local en el siglo xxI. Seguidamente se identificaron las estrategias de gestión ambiental en el desarrollo minero, la cuales se concretaron principalmente en marcos normativos y programáticos, que en su mayoría buscan promover un desarrollo minero sostenible asociado fundamentalmente a empresas transnacionales, ocasionando conflictos socioambientales.

Palabras clave: Quinchía, extractivismo, minería, gestión ambiental.

$\S \quad$ El presente artículo fue elaborado en el marco de la investigación Análisis Comparativo de los Procesos Interculturales de Construcción Territorial Agrícola y Minera en Quinchía. Casos de Estudio Corregimientos de Naranjal e Irra, realizada por la línea de investigación Estudios Socioculturales y Problemática Ambiental de la Universidad Tecnológica de Pereira. Sus objetivos específicos fueron: 1) caracterizar el patrimonio territorial en el corregimiento de Naranjal e Irra, 2) evaluar las estrategias de gestión ambiental territorial implementadas en los casos de estudio, y 3) explicar los espacios sociales de la configuración territorial en los corregimientos de Naranjal e Irra. Sin embargo, el presente documento deriva del análisis del segundo objetivo específico señalado.

* Estudiante de la Maestría en Sociedades Rurales de la Universidad de Caldas. Correo electrónico: yuliamsalas9@gmail.com 


\section{Environmental management strategies to deal with extractivist mining development in the municipality of Quinchía (Risaralda)}

Abstract: This article aims to analyze in the 21st century the main environmental management strategies implemented in the municipality of Quinchía (Risaralda), especially in the corregimientos of Naranjal and Irra, in front of extractive mining development.

To this end, first, a state of the art on extractive mining development was carried out in the national, departmental and local context in the 21st century. Next, environmental management strategies in mining development were identified. These strategies were mainly implemented in normative and programmatic frameworks, most of which seek to promote sustainable mining development, mainly associated with transnational corporations, leading to socio-environmental conflicts.

Keywords: Quinchía, extractivism, mining, environmental management.

Cómo citar este artículo: Salazar Duque, Yuliana (2017). Estrategias de gestión ambiental frente al desarrollo minero-extractivista en el municipio de Quinchía (Risaralda). Revista Controversia, 208, 137-150.

Fecha de recepción: 19 de enero del 2017

Fecha de aprobación: 26 de marzo del 2017

\section{Introducción}

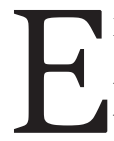

n Colombia, durante el siglo XxI, se consolida, aún con más fuerza, un modelo de desarrollo altamente dependiente de las exportaciones mineras, que se materializa en la concesión ilimitada de títulos sobre territorios de importancia ecosistémica y cultural. Esta visión de desarrollo ha centrado su interés en la promoción de reformas políticas y normativas propicias tendientes a garantizar la seguridad jurídica pertinente para el incremento de la inversión extranjera directa. Entre las principales ventajas normativas sobresalen las exenciones 
tributarias y la flexibilización de la reglamentación ambiental como incentivos a la atracción de capital foráneo (Fierro, 2012; Arias, 2013; Salazar, 2014).

Estas agendas nacionales se reflejan en departamentos como Risaralda, en especial en el municipio de Quinchía, un territorio de gran riqueza natural y diversidad cultural históricamente aquejado por la violencia. Con aproximadamente 33816 habitantes este municipio alberga 8843 indígenas pertenecientes a dos parcialidades, emberá chamí y emberá karambá, y a un resguardo, Escopetera y Pirza, constituido en Bonafont (Riosucio, Caldas), pero con población asentada en Quinchía (Ugarte et al. 2013, p.117). Aunado a la población indígena, el municipio está constituido por diversas organizaciones campesinas, mineras y sociales que buscan apropiarse material y simbólicamente de su territorio a través de procesos asociativos, como una alternativa frente a las condiciones sociales, económicas y políticas del municipio.

Quinchía, con más de un $80 \%$ de territorio rural, es uno de los municipios con mayor patrimonio minero en Risaralda. Asociado a las características mineralógicas, la actividad minera aurífera es desarrollada en más de veintiséis veredas por doce asociaciones mineras tradicionales, una cooperativa productora de carbón - Coocarboquin-, la Corporación Área de Reserva Especial Minera - Corpoare- y dos multinacionales extractivas con título de exploración (Batero Gold y Metminco Limited). Actualmente, más del $90 \%$ del territorio se encuentra solicitado o concedido para actividades de exploración y explotación minera (Salazar, 2014, p.62), situación que ha incidido en la configuración de conflictos territoriales.

Así pues, en el municipio de Quinchía, lugar con el más bajo índice de desarrollo humano en el departamento (DNP, 2005), la población se ha caracterizado principalmente por desarrollar actividades agrícolas ${ }^{1}$

1 De acuerdo con el Plan de Desarrollo Municipal 2012-2015, el municipio de Quinchía es predominantemente minifundista. Igualmente es importante resaltar que el 
y mineras. De manera que la agricultura ocupa el primer reglón, con plantaciones como el café, caña panelera, mora, plátano, cacao, aguacate, yuca, maíz y frijol, que abarcaba en el 2011 el 54,16\%² del total del suelo rural (Alcaldía Municipal, 2012a). Por su parte, la minería ocupa el segundo reglón económico y beneficia a más de 2000 personas 3 .

Con base en lo anterior, el presente artículo centra su interés en analizar las principales estrategias de gestión ambiental frente al desarrollo minero extractivista en Colombia, en especial en el territorio de Quinchía. De modo que, partiendo de las definiciones dadas por Guhl y Leyva (2015), Muriel (2006) y el Ministerio de Ambiente y Desarrollo Territorial (2007), se tomarán las estrategias de gestión ambiental como aquellas disposiciones, apuestas políticas y normativas que se materializan en instrumentos o acciones con influencia en el desarrollo minero-extractivista y, por ende, en las condiciones socioambientales del territorio. Es este referente teórico el que posibilitó identificar las principales estrategias de gestión ambiental de tipo sectorial y territorial que han servido, en su mayoría, como dispositivos para legitimar el desarrollo minero-extractivista.

\section{Desarrollo minero extractivista en Colombia}

El desarrollo minero en Colombia, posterior a la apertura económica de César Gaviria Trujillo (1990-1994), se transformó en uno de los pilares económicos estratégicos del país. Mediante el Plan Nacional de Desarrollo La Revolución Pacífica (1990-1994), se instauraron estrategias impartidas en el Consenso de Washington (1989) que promocionaron el extractivismo minero del país (Fierro, 2012, p.16).

municipio alberga once organizaciones agrícolas (Ugarte et al., 2013).

2 Quinchía cuenta con $141 \mathrm{~km}^{2}$, pero tan solo $0,798 \mathrm{~km}^{2}$ representa el área urbana.

3 Véase "Minería sí, pero que sea responsable con el ambiente", alcalde de Quinchía. http://www.eldiario.com.co/seccion/RISARALDA/miner-a-s-pero-que-sea-responsable-con-el-ambiente-alcalde-de-quinch-a1703.html 
El Consenso de Washington estableció una receta genérica para que los países latinoamericanos alcanzaran un mayor desarrollo, a saber: la liberalización de los mercados, la eliminación de barreras comerciales y el incentivo a la inversión extranjera. Estas agendas globales incluyeron la modificación de los códigos mineros de la mayor parte de Latinoamérica en la década de 1990, y en Colombia la derogatoria del Decreto 2655 de 1988, reemplazado por el código de Minas Ley 685 de 2001 (Fierro, 2012, p.16).

A finales del siglo xx y durante el siglo XXI en Colombia se impulsan una serie de reformas políticas y normativas con ayuda de organismos internacionales canadienses como el Canadian International Development Agency —CIDA - y Canadian Energy Research Institute —CERI-; esta última, desde 1997, intervino en la formulación del Código de Minas Ley 685 de 2001 (Fierro, 2012, p. 36; Arias, 2013, p.54), código que hace "uso de la figura de contrato de concesión como único sistema para traspasar a empresarios privados, preferiblemente a corporaciones transnacionales, el derecho a explorar y explotar los yacimientos mineros del país por un porcentaje pírrico de regalías” (Arias, 2013, p.54).

Asimismo, diferentes planes de desarrollo: Hacia un Estado Comunitario (2002-2006), Estado Comunitario: Desarrollo para Todos (20062010), Prosperidad para Todos (2010-2014), Todos por un Nuevo País. Paz, Equidad y Educación (2014-2018) han propendido por una economía competitiva, fundamentada en el extractivismo, que se ha visto reflejada en la concesión ilimitada de títulos en zonas de importancia ecosistémica y sociocultural para el país.

Todos estos planes de desarrollo nacional han tenido como fin principal aumentar la inversión extranjera, mediante ajustes normativos y políticos orientados, fundamentalmente, a generar beneficios jurídicos y financieros a favor de capital privado y empresas transnacionales.

En coherencia con los anteriores planes de desarrollo surge el interés de impulsar una minería ambiental y socialmente responsable como 
eje del desarrollo sostenible del país, manifestada en cada una de las políticas que rigen la implantación de un modelo extractivista como motor económico de la nación. A través de la promoción de la minería ambiental y socialmente responsable, asociada esencialmente a las empresas transnacionales, se legitima la explotación de riquezas naturales a lo largo del territorio nacional.

Así, la Unidad de Planeación Minero-Energética -Upme- publica en el año 2002 el Plan Desarrollo Minero (2002-2006); posteriormente, en el año 2006, Colombia País Minero, Plan Nacional para el Desarrollo Minero Visión al año 2019 y, en el año 2007, el Plan Nacional de Desarrollo Minero (2007-2010) Gestión Pública para Propiciar la Actividad Minera. Estos tres planes pretenden promover la actividad minera responsable para el desarrollo sostenible del país. Entre tanto, cabe resaltar que este despliegue estratégico privilegia la mercantilización de la naturaleza hacia el capital extranjero sobre los intereses sociales, culturales y ambientales de territorios con riquezas minerales.

El Ministerio de Minas y Energía impulsa políticas sectoriales como Administración del Recurso Minero (2006), Mejoramiento de la Productividad y Competitividad del Sector (2008), Promoción del País Minero, Formalización Minera (2014) y Seguridad Minera, con incidencia a lo largo del territorio colombiano.

Frente a lo anterior, es importante señalar que el Ministerio de Minas hace efectiva, mediante la Resolución número 40391 de 20 de abril de 2016, la Política Minera Colombiana- Bases para la Minería del Futuro: un documento que recoge las diferentes políticas y lineamientos existentes en el país, lo que la transforma en la política minera única integral de Colombia. Esta política ratifica que, entre las principales preocupaciones gubernamentales, se encuentra hacer de la minería en Colombia un sector competitivo, con alta seguridad jurídica, para la atracción de capital privado nacional e internacional. 
Todas estas directrices políticas y normativas obedecen a intereses geopolíticos de control territorial y del patrimonio natural que configuran el interés de impulsar una minería ambiental y socialmente responsable como eje del desarrollo sostenible del país.

En efecto, estas políticas privilegian el desarrollo minero como estrategia para el crecimiento económico sostenible, basándose en la noción de minería ambiental y socialmente responsable. El desarrollo sostenible, acuñado por primera vez en el Informe de la Comisión Brundtland (1987), constituye una táctica discursiva adoptada por organismos internacionales y nacionales para el aprovechamiento de la riqueza natural de países como Colombia.

Previa emisión del Informe Brundtland (1987), "la idea de límites ambientales al crecimiento económico habría generado la percepción de que economía y ecología eran dos campos irreconciliables. En cambio, la Comisión revierte ese enfrentamiento, sosteniendo que la conservación ambiental es necesaria para mantener el crecimiento económico" (Gudynas, 2011, p.72). De esta manera, el desarrollo sostenible empieza a ser adoptado por distintos agentes gubernamentales, académicos, privados y sociales para revestir el propósito de crecimiento económico ilimitado con la noción de sostenibilidad ambiental.

En consecuencia, el enfoque de sostenibilidad ambiental se transforma en imperativo del desarrollo de la industria minera en Colombia. Bajo este manto discursivo se legitima la implementación de estrategias gubernamentales y corporativas para la instalación de proyectos extractivos que configuran a su vez conflictos ambientales mineros.

La responsabilidad social y ambiental, como un apelativo al crecimiento económico sostenible, se suscribe en una estrategia corporativa que busca consagrar en los lugares de operación de los proyectos extractivos el desarrollo de la minería como promotora de beneficios sociales y económicos. 
Asimismo, entre las estrategias de gestión ambiental desplegadas desde el ámbito internacional frente al desarrollo minero-extractivista con incidencia en el contexto colombiano se encuentran:

- Proyecto Mesoamérica para la Integración y el Desarrollo - PMy Proyecto de Integración de la Infraestructura Regional Suramericana -IIRSA - que se enfocan en promover la integración de sectores de transporte, energía y comunicaciones, atrayendo mayor inversión al desarrollo minero-energético.

- La adopción por parte de Colombia de iniciativas propuestas por la Organización para la Cooperación y Desarrollo Económico — OCDEcon el propósito de que no exista "contradicción alguna entre las actividades de las empresas multinacionales y el desarrollo sostenible" (OCDE, 2011, p.24) alentando la atracción de inversión extranjera mediante la elaboración conjunta de políticas y regulaciones (OCDE, 2011, p.24).

- La promoción de propuestas como Estándares de la Iniciativa para la Transparencia de las Industrias Extractivas —EITI-, desarrolladas conjuntamente entre agencias multilaterales y gubernamentales para legitimar, mediante el discurso de la sostenibilidad y la responsabilidad social, la implementación de proyectos extractivos de gran envergadura.

- La adopción del discurso de responsabilidad social y ambiental por parte organismos como el Consejo Internacional de Minería y Metales -ICMM-, integrado por veintitrés empresas, como estrategia de legitimación corporativa.

Sumado a lo anterior, la apuesta gubernamental por una economía fundada en el crecimiento de la minería sostenible o responsable también se materializa en aspectos normativos como: 
- La Resolución No. 180241, 0045 de 2012 y la Resolución No. 429 de 2013, proferidas por el Ministerio de Minas y Energía y la Agencia Nacional de Minería - ANM - , a través de las cuales se declararon las Áreas Estratégicas Mineras — AEM - y se delimitaron quinientos dieciséis bloques sobre más de veinte millones de hectáreas del territorio nacional, que afectaron a los departamentos de Antioquia, Bolívar, Caldas, Cauca, Cesar, Chocó, Huila, La Guajira, Nariño, Norte de Santander, Putumayo, Quindío, Risaralda, Tolima, Valle del Cauca, Amazonas, Guainía, Guaviare, Vaupés y Vichada. Dichas resoluciones fueron declaradas inexequibles por la Corte Constitucional mediante la Sentencia T-766-2015.

- El Decreto 0934 del 9 de mayo de 2013, por medio del cual se reglamentó el artículo 37 de la Ley 685 de 2001, el cual mencionaba que la decisión de establecer zonas excluidas de la minería es competencia exclusiva de las autoridades minera y ambiental. Sin embargo, dicho artículo fue declarado inexequible por la Corte Constitucional, que mediante la Sentencia C-273/16 ordenó que las decisiones sobre la titulación del subsuelo deben ser acordadas con las autoridades municipales.

- Los artículos 108 de la Ley 1450 de 2011 y 20 de la Ley 1753 de 2015, los cuales crearon y ampliaron la figura de las Áreas de Reserva Estratégicas Mineras -AEM-; los artículos 49, 50 (parcial), 51 y 52 (parcial) de la Ley 1753 de 2015, que desarrollaron el Sistema de Proyectos de Interés Nacional y Estratégico —Pines-; y el parágrafo del artículo 173 de la Ley 1753 de 2015, que reguló las actividades extractivas en ecosistemas de páramo. Frente a los artículos anteriores, la Corte Constitucional emitió la Sentencia C-035/16 por medio de la cual reiteró la prohibición de hacer minería en los páramos e hizo hincapié en la posibilidad de decisión de autoridades locales respecto a las actividades económicas que se realicen en sus territorios. 
- Decreto 2041 de $2014^{4}$, concerniente a las licencias ambientales exprés, el cual reglamenta la entrega de permisos ambientales en tiempo récord para el desarrollo de proyectos extractivos, y una flexibilización normativa atractiva para el capital privado y transnacional.

- El Decreto 2691 de 23 de diciembre de 2014, también conocido como Decreto Navideño, suspendido el 2 de julio de 2015, el cual estableció medidas para que las autoridades locales municipales determinaran con estudios técnicos, incorporados en sus planes de desarrollo, las zonas de importancia ecosistémica que deberían ser solicitadas para su protección ante el Ministerio de Minas y Energía. Este, de considerarlo necesario, acudiría al Departamento Nacional de Planeación o a aquellas empresas o gremios mineros que tengan interés en el área.

- El Decreto 0276 de 17 de febrero de 2015, que estableció como obligatorio el Registro Único de Comercializadores Mineros - Rucom-, otorgado a los mineros formales, o en proceso legalización, para la venta o compra del mineral extraído. Este decreto, asociado con otras normas de formalización, afectó el desarrollo de la minería tradicional.

- Pretensiones para constituir una ley de delitos ambientales que tendría incidencia en más de veintidós departamentos donde se realiza minería de hecho.

En síntesis, todas estas estrategias de gestión ambiental sectorial y territorial desplegadas por agentes gubernamentales y corporativos se enfocan en defender la minería sostenible como mecanismo para el crecimiento económico del país. En ese sentido, son apuestas políticas y

4 Véase Piden suspender decreto de licencias ambientales. Disponible en: http:// www.elespectador.com/noticias/medio-ambiente/piden-suspender-decreto-delicencias-ambientales-articulo-543568 
normativas que han privilegiado la inversión extranjera, principalmente transnacional, sobre la minería tradicional, la autonomía territorial de las comunidades locales, la defensa de los derechos humanos y la protección del patrimonio natural de la nación.

\section{Desarrollo minero extractivista en el departamento de Risaralda}

En este contexto, la promoción del desarrollo extractivista minero permea las agendas departamentales, las cuales adecuan sus estrategias políticas a las necesidades de índole nacional e internacional. Así, un departamento como Risaralda, localizado en el centro occidente de Colombia, concentra sus esfuerzos, entre otros aspectos, en hacer de la minería un sector competitivo, como se manifiesta en el siglo XXI en diferentes planes de Gobierno: el Plan Departamental Risaralda Desarrollo con Rostro Humano y Social en Igualdad de Oportunidades (2001-2003), el Plan de Desarrollo Departamental Risaralda, Sentimiento de Todos (2008-2011), el Plan de Desarrollo Risaralda: Unida, Incluyente y con Resultados (2012-2015) y el Plan de Desarrollo Risaralda Verde y Emprendedora (2016-2019).

El Plan de Desarrollo Departamental Risaralda Desarrollo con Rostro Humano y Social en Igualdad de Oportunidades (2001-2003) estableció en una de sus líneas el Programa de apoyo al desarrollo de la minería, el cual propuso "promover proyectos de aprovechamiento sostenible minero y acciones que generen alto impacto en el desarrollo de las comunidades mineras" (Gobernación de Risaralda, 2001, p.71). En consonancia, se plantearon tres subprogramas como estrategias de gestión ambiental orientadas al desarrollo minero: 1) Ordenamiento institucional y organizativo del sector minero, 2) apoyo a la industrialización de la pequeña y mediana minería, y 3) gestión ambiental para la sostenibilidad de la producción minera (Gobernación de Risaralda, 2001) 
Por su parte el Plan de Desarrollo Departamental Risaralda, Sentimiento De Todos (2008-2011) afirma:

El desarrollo minero en el departamento de Risaralda se considera muy bajo, tanto en términos de exploración, explotación y beneficio, como en su participación en la economía del Departamento; adicionalmente, la disminución en las actividades de aprovechamiento de los recursos minerales y la escasa tecnología utilizada, ha generado que la minería en los últimos años sea vista como artesanal, atrasada y con poca representatividad en la generación de empleo y desarrollo local (Gobernación de Risaralda, 2008, p.77)

En el marco de estas consideraciones, dicho plan de desarrollo estableció como necesaria la puesta en marcha del subprograma: La minería, factor social en el desarrollo económico, con el propósito de incentivar, la productividad y competitividad como bases del crecimiento sostenible del sector minero en el departamento de Risaralda.

Estos planes departamentales enuncian estrategias y acciones tendientes a mejorar la productividad de la minería, a través de la inversión en procesos técnicos y organizativos para consolidar un sector minero con oportunidad hacia el desarrollo de la economía regional y nacional.

En coherencia con los anteriores planes de desarrollo departamentales, en el año 2010 se conformó el Distrito Minero de Risaralda, integrado por los municipios de Mistrató, Pueblo Rico, Quinchía, Apía y La Virginia, el primero de 38 distritos coordinado por una Gobernación. Al respecto, el entonces gobernador de Risaralda, Víctor Manuel Tamayo Vargas, enunció:

Es hora de aprovechar la riqueza que existe en todos los rincones de las ricas tierras risaraldenses, donde encontramos minerales como el oro, el carbón y el manganeso [...]. El Distrito Minero permitirá consolidar un esquema de alta gestión para el sector, generando verdaderas herramientas 
para hacer de Risaralda un departamento emprendedor, donde la minería se presenta como un eje potenciador de la economía (Gobernación de Risaralda, 2010).

El Distrito Minero, enfocado en el mejoramiento de la productividad y competitividad de la minería en Risaralda, buscó aprovechar el potencial geológico del departamento, con la intención de generar mayor crecimiento económico de la región. En palabras del entonces gobernador "queremos que Risaralda sea un departamento minero que brille con luz propia” (Ossa, 2010).

Por su parte, Martha Pachón, actual encargada del programa de Responsabilidad Social de la Secretaría de Desarrollo Económico de la Gobernación de Risaralda, quien se desempeñó como directora del Distrito Minero, señaló que "los distritos mineros eran una política de productividad y competitividad del Ministerio de Minas a nivel nacional que en Risaralda se creó en el 2010, pero solo duró un año” (Entrevista realizada a Martha Pachón, 2016). Sin embargo, con el ánimo de propender por una minería sostenible, la Gobernación de Risaralda continúo con el Programa de responsabilidad social consolidado "desde el año 2007 con el objetivo de asesorar, apoyar, capacitar y brindar asistencia técnica a todo el sector minero en el departamento" (Entrevista realizada a Martha Pachón, 2016). Para el año 2010, periodo en que fue declarado el Distrito Minero de Risaralda ${ }^{5}$, Quinchía sobresalía en la solicitud y concesión de títulos mineros (ver tabla 1).

De conformidad con lo anterior, el Plan de Desarrollo Risaralda: Unida, Incluyente y con Resultados (2012-2015), constituido por el programa

5 En el año 2013, se instaló en Risaralda la mesa departamental Minería Responsable y Sostenibilidad Ambiental, en la cual Juan Manuel Álvarez Villegas, director de la Corporación Autónoma Regional de Risaralda, señaló: "Bienvenida la mesa minero ambiental a Risaralda. La minería responsable lleva a un desarrollo social, económico y ambiental del departamento, y desde la CARDER debemos apoyar la legalidad minera en armonía con el ambiente” Disponible en http://www.carder. gov.co/app/webroot/index.php/cmsnews/webShow/496\#sthash.2vUJk6BT.dpuf 


\section{Tabla 1. Títulos y solicitudes mineras en Risaralda (2010)}

\begin{tabular}{|l|c|c|}
\hline \multicolumn{1}{|c|}{ Municipio } & Total títulos & Total solicitudes \\
\hline Quinchía & 16 & 91 \\
\hline Pereira & 15 & 60 \\
\hline Mistrató & 0 & 69 \\
\hline Santa Rosa de Cabal & 11 & 59 \\
\hline Santuario & 7 & Sin dato \\
\hline Balboa & 7 & 37 \\
\hline Pueblo Rico & Sin dato & 43 \\
\hline Otros & 10 & 43 \\
\hline Total general: & 66 & 402 \\
\hline
\end{tabular}

Fuente: Catastro Minero Colombiano. Febrero de 2010

Risaralda Estratégica, Competitiva y con Resultados, integrado a su vez por el subprograma Minería Socialmente Responsable y Sostenibilidad Socioambiental, tendió a "fortalecer las empresas del sector minero, teniendo en cuenta el pacto global, la responsabilidad social empresarial, la asociatividad, la legalidad y el desarrollo de una minería social y jurídicamente responsable” (Gobernación de Risaralda, 2012, p.62).

El actual Plan de Desarrollo Departamental Risaralda: Verde y Emprendedora (2016-2019) propone como estrategia para la acción el despliegue de seis capitales, entre los que sobresale el capital económico, que establece como uno de los subprogramas el de la productividad empresarial enfocado a "promover procesos que generan encadenamientos empresariales efectivos, para el desarrollo de alianzas empresariales orientadas al incremento de la productividad y la competitividad" (Gobernación de Risaralda, 2016, p.96). Entre las metas de este objetivo, se destaca la necesidad de "fortalecer técnica, administrativa y financieramente la cadena productiva del sector minero del departamento de Risaralda” (Gobernación de Risaralda, 2016, p.97) 


\section{Desarrollo minero extractivista en el municipio de Quinchía (Risaralda)}

\section{Minería tradicional y desarrollo minero multinacional}

Estas agendas nacionales y departamentales se reflejan particularmente en el municipio de Quinchía, localizado en el nororiente de Risaralda, el cual constituye uno de los principales territorios con riqueza mineral en el departamento (ver mapa 1). Dicho municipio cuenta con una población 33816 habitantes (Alcaldía de Quinchía, 2016) distribuida predominantemente en 80 veredas que conforman la zona rural; población que, a su vez, se encuentra integrada por más de 8843 indígenas pertenecientes a las parcialidades emberá chamí, emberá karambá y al resguardo Escopetera y Pirza (Ugarte et al. 2013, p.117).

\section{Mapa 1. Localización Geográfica de Quinchía, Risaralda}

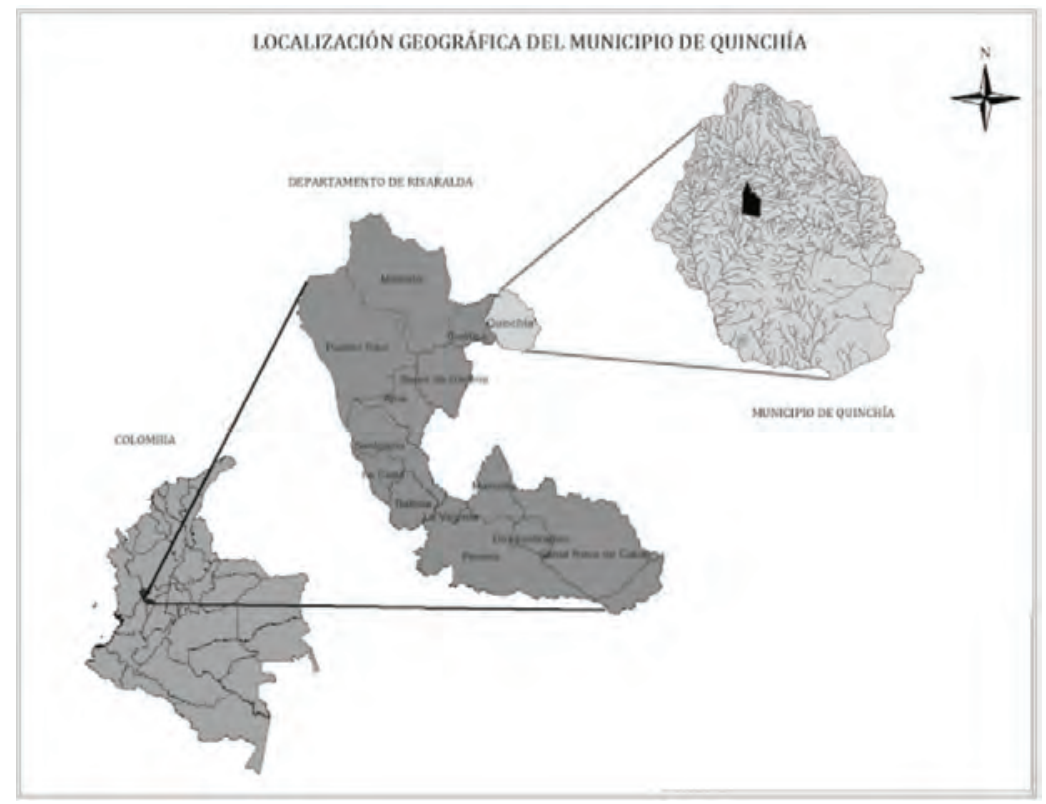

Fuente: Salazar, 2015 


\section{Mapa 2. Localización de los corregimientos de Naranjal e Irra}

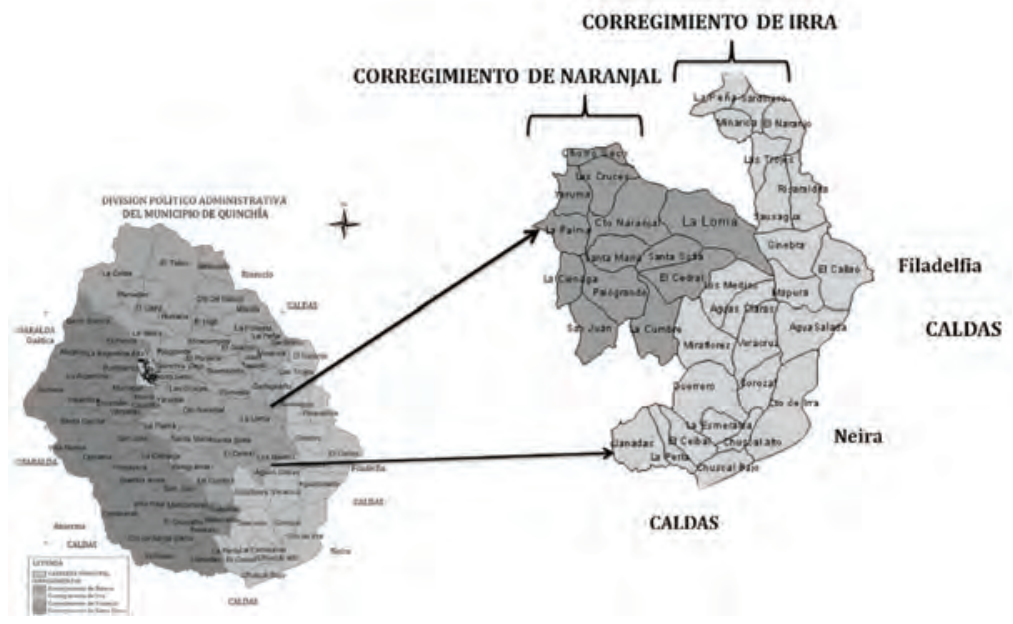

Fuente: Modificado de Salazar, 2015

El municipio de Quinchía, predominantemente rural, está conformado por cuatro corregimientos: Batero, Santa Elena, Irra y Naranjal. Estos dos últimos, con presencia de títulos de exploración a cargo de empresas mineras (ver mapa 2).

Este municipio, de larga tradición minera, presentaba en el año 1999, según el diagnóstico del Plan Básico de Ordenamiento Territorial —PBOT, quince áreas de producción minera que comprendían más de 800 hectáreas. Por tal razón, el Рвот estableció el artículo 36 -Usos de la actividad minera-, en cual señaló los referentes ambientales que debían ser considerados "para lograr optimizar la explotación racional y sostenible del sector minero” (p.38). Entre los aspectos más sobresalientes se identifican restricciones ambientales para desarrollar la minería y la motivación por realizar un plan ambiental minero.

La tradición minera de este municipio mantuvo su importancia para el año 2013, pues en este periodo se registraba la presencia de 19 asocia- 
ciones mineras tradicionales enfocadas en la extracción de oro, además de dos áreas de reserva especial ${ }^{6}$ Corpoare y Coocarboquin, dedicadas al aprovechamiento de oro y carbón, respectivamente. Del total de las asociaciones mineras, 14 se encontraban localizadas en los corregimientos de Naranjal e Irra. Es importante señalar que muchas de estas organizaciones han desaparecido o se encuentran inactivas (ver mapa 3).

\section{Mapa 3. Asociaciones mineras tradicionales en Naranjal e Irra. Año 2013.}

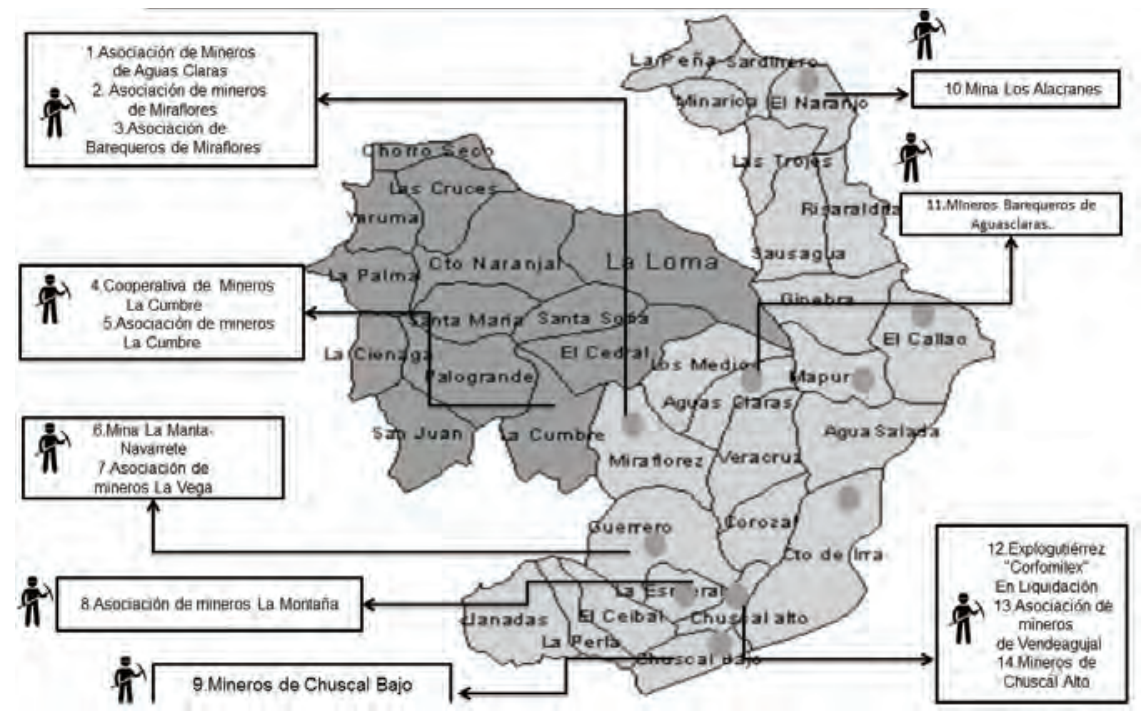

Fuente: Realizado con base en el Plan de Desarrollo Municipal 2012-2015.

En contraste con la minería tradicional se encuentran dos multinacionales extractivas, con título de exploración: Batero Gold, localizada en la

6 Las Áreas de Reserva Especial, de acuerdo con el artículo 31 de la Ley 685 de 2001, son áreas con existencia de explotaciones tradicionales de minería informal definidas conforme al artículo 257 del Código de Minas. 
vereda La Cumbre, en el corregimiento de Naranjal, y Metminco Limited $^{7}$, localizada en Miraflores, en el corregimiento de Irra (ver mapa 4).

\section{Mapa 4. Empresas mineras multinacionales}

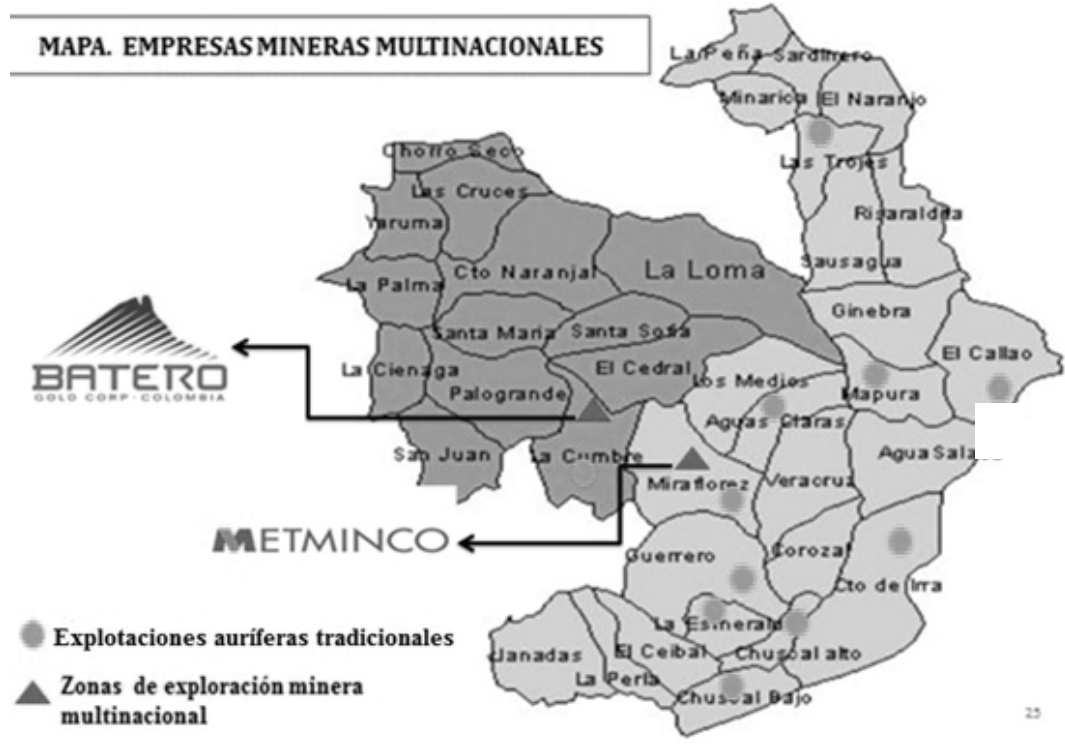

Así pues, el interés sobre el potencial geológico del municipio de Quinchía, donde en veintiséis de sus veredas alrededor del $60 \%$ de los pobladores dependen directamente de dicha actividad minera (Alcaldía de Quinchía, 2012a, p.77), se convierte en la principal motivación de las administraciones locales para fomentar el desarrollo de la minería. De esta manera lo muestran los planes de desarrollo municipal: 1) En Marcha Hacia un Mejor Futuro (2001-2003), 2) Una Alcaldía con Compromiso Social (2004-2007), 3) Todos por Quinchía con Acción y Decisión

7 Al respecto se recomienda visitar la página http://www.metminco.com.au/site/ projects/quinchia-gold-portfolio 
(2008-2011), 4) Quinchía para Todos (2012-2105), y 5) Quinchía Primero (2016-2019).

El plan de desarrollo de Quinchía En Marcha Hacia un Futuro Mejor (2001-2003) propuso el programa Apoyo a los Mineros, que buscaba prestar asistencia técnica a los mineros tradicionales, fortalecer la comercialización del oro y realizar acciones tendientes a mitigar los impactos ambientales de la minería (Alcaldía de Quinchía, 2001, p.166).

Para este momento, se identificaban importantes reservas auríferas de veta en los corregimientos de Irra (centro poblado, veredas de Miraflores, Guerrero, Las Trojes, El Chuscal, El Ceibal y El Callao), Naranjal (vereda la Cumbre) y Batero (veredas Sardinero, Juan Tapao y Mina Rica). Es importante mencionar que en esta época ya se registraban estudios mineros del Gobierno nacional y de particulares (Alcaldía de Quinchía, 2001, p.159).

Sumado a la riqueza aurífera, el municipio de Quinchía buscaba potenciar la extracción de minerales como el carbón, aprovechado esencialmente en las veredas Encenillal y Opiramá. En este contexto, en el que entró en vigor el nuevo Código de Minas, Ley 685 de 2001, el departamento de Risaralda inició el proceso de liquidación de la empresa estatal minera de Risaralda, Mineralda, que se encontraba constituida desde el año 1996. Entre los aspectos que serían modificados por el Código de Minas se destaca el papel del Estado. Este pasó de participar en el manejo del sector minero a cumplir las funciones de regular, promover y fiscalizar la intervención del sector privado mediante la flexibilización de las normas que permiten acceder al título minero para la exploración y explotación del recurso (Pardo, 2013, citado en Salazar, 2014, p.18).

En coherencia con el propósito del Código de Minas de incentivar la exploración y explotación de los minerales de propiedad estatal y privada en Colombia, el Plan de Desarrollo Municipal Una Alcaldía con 
Compromiso Social (2004-2007) estableció en uno de sus programas: "fomentar la minería y los recursos naturales como compromisos de oportunidad y desarrollo sobre la base de la sostenibilidad ambiental" (Alcaldía de Quinchía, 2004a, p.10).

En este periodo, el Gobierno nacional y algunas empresas multinacionales habían adelantado estudios en exploración de yacimientos minerales. Empresas como Tvx Minera y Anaconda Golds habían realizado solicitudes de áreas y licencias de exploración (Alcaldía de Quinchía, 2004a, p.49). De acuerdo con uno de los integrantes de Corporae de Quinchía, “desde 1990 había una empresa llamada TVX, quienes tenían solicitudes, pero no habían hecho presencia en la zona debido a las condiciones de violencia” (Entrevista realizada a Sonier Obando, 2014).

En la década de 1990, la compañía canadiense productora de oro de nivel medio ${ }^{8}$ Tvx Gold Inc, evaluó el área de Miraflores, pero las condiciones de orden público fueron la principal limitación para realizar los programas de exploración planificados (Baldys y Anderson, 2009, citados en Pardo y Salazar, 2013, p.15). Entre las veredas más aquejadas por la violencia se encuentra la zona minera de Miraflores, donde se han realizado explotaciones tradicionales de tipo filón desde el año 1986 por parte de la Asociación de Mineros de Miraflores, con un título de explotación adquirido en el año 1987 y vendido a la empresa minera Seafield en el año 2011.

Para ese momento, en el municipio hacían presencia grupos armados como los Magníficos (1984 y 1990) y el Ejército Popular de Liberación —EPL-, este último liderado desde 1999 por el dirigente nacido en Quinchía Berlaín Chiquito Becerra, también conocido como Leyton,

8 De acuerdo con Ponce (2012), una empresa minera intermedia es aquella que tiene un ingreso anual superior a US\$50 millones, pero inferior al umbral de US\$500 millones (p.198). 
asesinado por el Ejército Nacional en el año 2006 (Sánchez, 1983; Cardona, 1989; Parra, 2010).

Iniciando el siglo XXI, en el marco de la Política de Seguridad Democrática, se llevaría a cabo en el año 2003 la “Operación Libertad”, que consistió en la detención arbitraria de más de cien moradores de Quinchía por presuntos nexos con la guerrilla del EPL. Sin embargo, tiempo después fueron liberados tras ser encontrados inocentes ${ }^{9}$.

Sumado a lo anterior, entre los años 2002 y 2006 hizo presencia el grupo de las Autodefensas Unidas de Colombia denominado Bloque Central Bolívar, el cual incidió en el desplazamiento de más de 1491 personas en el año 2004. Quinchía, después de Pueblo Rico, según la Unidad para la Atención y Reparación Integral a Víctimas (2013, p.102) es el municipio con más desplazados registrados entre 1985-2012.

En este contexto, para el año 2004, la administración municipal registraba que un $86 \%$ de las actividades mineras realizadas en el territorio de Quinchía no eran formalmente reconocidas por el Estado, en contraste con un 14\% que sí lo estaban (Alcaldía de Quinchía, 2004, p.50). En ese entonces, se registraban doce asociaciones y cooperativas de mineros tradicionales (Alcaldía de Quinchía, 2004a, p.53). Un año después, en el 2005, llegaría al municipio la empresa multinacional Sociedad Kedahda S.A. filial de la sur africana AngloGold Ashanti.

En coherencia con lo anterior, en lo que respecta al sector minero, el Plan de Desarrollo Todos por Quinchía con Acción y Decisión (20082011) propuso como objetivo general “mejorar la producción de los mineros y consolidar este sector como un renglón importante de la economía municipal”. Para tal fin estableció, "entre otros aspectos, el apoyo al pequeño minero de oro, así como el mejoramiento técnico, la educación y el medio ambiente” (Alcaldía de Quinchía, 2008, pp.124 y 196).

9 Véase el libro Boleta de Captura de Aldemar Solano. 
Tras la instalación de la empresa Sociedad Kedahda S.A., el Plan de Desarrollo Municipal Todos por Quinchía con Acción y Decisión (20082011) exhortó dentro de su exposición de motivos a desarrollar una minería responsable, con prelación de la tradición cultural y la protección ambiental:

Hay que revisar de una manera responsable y consciente el advenimiento de empresas de exploración minera, exigiendo de una manera cordial y amigable los compromisos de respeto hacia la tradición y derechos de los cabildos, el cuidado del medio ambiente y la no afectación del entorno, pues este tema nos preocupa de una manera responsable no tanto actualmente sino hacia el futuro (Alcaldía de Quinchía, 2008, p. 9).

Asimismo, para el sector minero, este plan de desarrollo estableció objetivos como: 1) convertir esta actividad en segura y promisoria, 2) mejorar las condiciones de vida de los mineros y del entorno que los rodea, y 3) acompañar y ayudar a otros sectores productivos en minería.

En contraste con las declaraciones anteriores, el mismo plan de desarrollo municipal emitió pronunciamientos que, por un lado, desestimulaban la minera tradicional y, por otro, estimulaban la presencia de entes multinacionales. En primer lugar, la desestimulación de la minería tradicional se observa claramente en el siguiente apartado:

Desde el año 2000 el municipio empezó a invertir decididamente en este sector con la conformación de los grupos o núcleos mineros, los cuales eran asociaciones de campesinos [...]. Estas asociaciones y otras particulares han recibido apoyo del Estado, pero no han logrado consolidarse como verdaderas empresas mineras y generalmente causan daños graves al ecosistema por sus costumbres y formas de obtención del oro a través de la utilización de mercurio y cianuro de sodio (Alcaldía de Quinchía, 2008, p.60). 
La estimulación de la presencia de compañías transnacionales se avizora en el siguiente apartado:

Con la llegada de la multinacional Kedhada al municipio se han sembrado nuevas esperanzas en el sector, pues hay perspectivas de producción en algunas zonas, para ello esta empresa desde 2004 viene haciendo trabajos de exploración. En su afán de ser aceptados por la comunidad han emprendido una serie de inversiones sociales que han ayudado al municipio en esas zonas a cubrir parte de sus obligaciones y han beneficiado directamente a la comunidad rural de las veredas donde ellos hacen presencia (Alcaldía de Quinchía, 2008, p.61).

Por su parte, el Plan de Desarrollo Quinchía para Todos (2012-2015) estableció como meta del programa Sector Productivo para Todos: "ofrecer a los quinchieños las garantías para la explotación del suelo rural, mediante la ejecución de proyectos productivos que permitan la vinculación de mano de obra en todas las familias; de igual forma, el estímulo a la actividad minera desarrollada por los pequeños y grandes mineros” (Alcaldía de Quinchía, 2011, p.159).

En coherencia con estas apuestas de desarrollo, arribaron otras empresas multinacionales júnior al municipio de Quinchía ${ }^{10}$. Así, la Sociedad Kedahda S.A., adquirió títulos que en el año 2007 fueron vendidos a la canadiense B2 Gold Corp y, posteriormente, en el 2009, a la Batero Gold Corp y a la Minera Seafield Resources; esta última fue adquirida el veinte de junio de 2016 por Metminco Limited, que cambió el nombre de Minera Seafield a Miraflores Compañía Minera S.A.S ${ }^{11}$. La Batero Gold (ver

10 Es importante recordar que las empresas júnior "se caracterizan por realizar actividades de exploración y producción mediante la financiación de capital accionario de equity financing" (Ponce, 2012).

11 La compañía completó la compra de Minera Seafiled S.A.S. de RMB Australia Holdings Limited —RMB- el 20 de junio de 2016. Minera Seafield, ahora Miraflores Compañía Minera S.A.S. — MCM-, posee el 100\% del Quinchía Gold Project 


\section{Mapa 5. Área titulada a la empresa Minera Seafield adquirida por Metminco Limited}

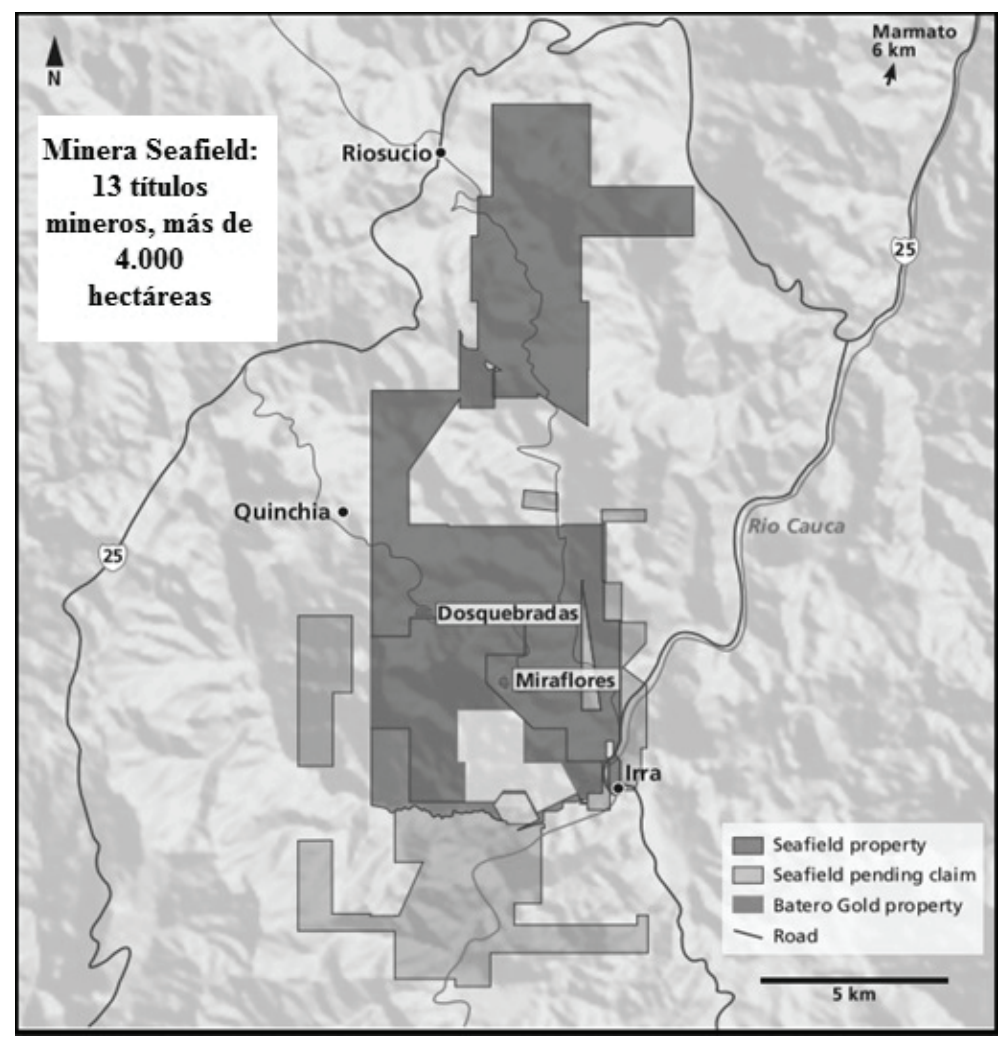

Fuente: http://www.sffresources.com/ Sitio web de la empresa Minera Seafield Resources Ltd, 2016

mapa 6) y Metminco Limited (ver mapa 5) también obtuvieron títulos ${ }^{12}$

(“Quinchía Portafolio”) Véase http://www.metminco.com.au/site/projects/quinchia-gold-portfolio

12 Según la entrevista realizada a Giovany Ortiz, gerente de exploración de la empresa Metminco Limited, antes Seafield Resources: "primero eran 10 títulos, luego subió 


\section{Mapa 6. Área titulada a la empresa Batero Gold}

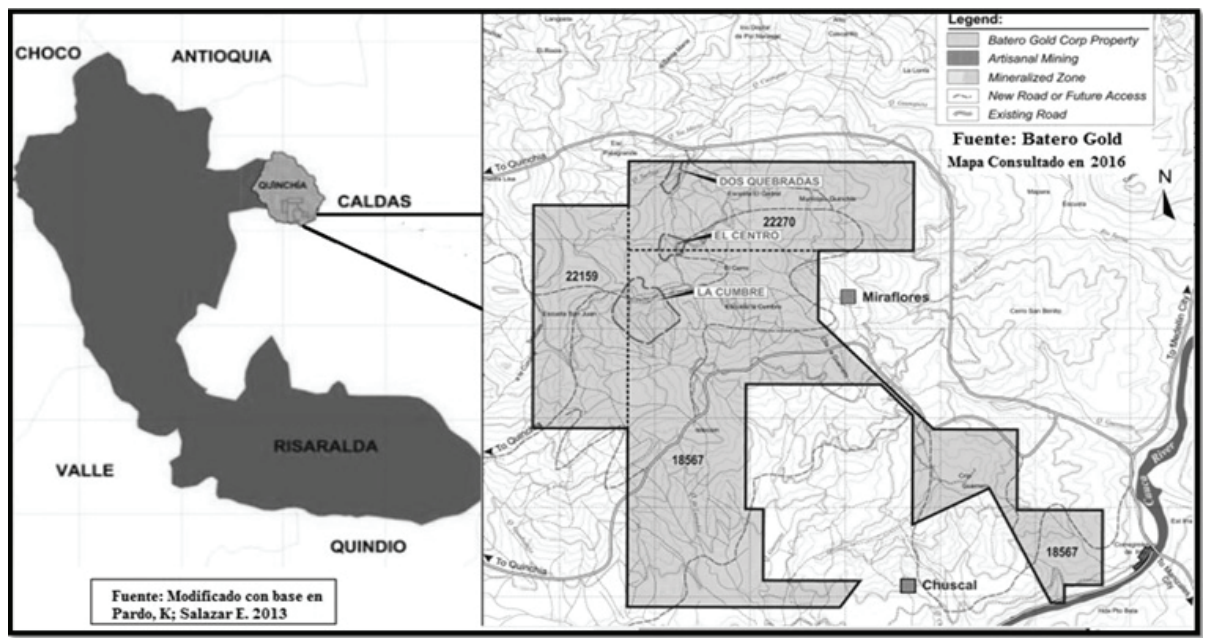

Fuente: Realizado con base en Pardo y Salazar, 2013 y

Página de la empresa Batero Gold

http://baterogold.com/projects/quinchia-project , 2016

de exploración en las veredas la Cumbre, del corregimiento de Naranjal, y las veredas Dosquebradas y Miraflores del corregimiento de Irra.

Para el año 2014, en Quinchía se habían otorgado 20 títulos mineros a 9 titulares entre los que sobresalían las empresas Minera Seafield S.A.S., Sociedad Minera Quinchía S.A.S. y Anglo Gold Ashanti Colombia S.A. A su vez, para el 2014, se habían realizado 51 solicitudes de títulos mineros, 18 de las cuales eran solicitudes de legalización y 33 para la adquisición de contratos de concesión (Catastro Minero Colombiano, 2014, citado en Salazar, 2014, p.116). En el 2015 se registraron 81 solicitudes (Catastro Minero Colombiano, 2015). En suma, las solicitudes

a 13 [...]; en área pueden abarcar aproximadamente cuatro mil hectáreas, que pueden aumentar o disminuir, eso depende de lo que se vaya realizando" (2016). 


\section{Mapa 7. Títulos y solicitudes mineras en Quinchía}

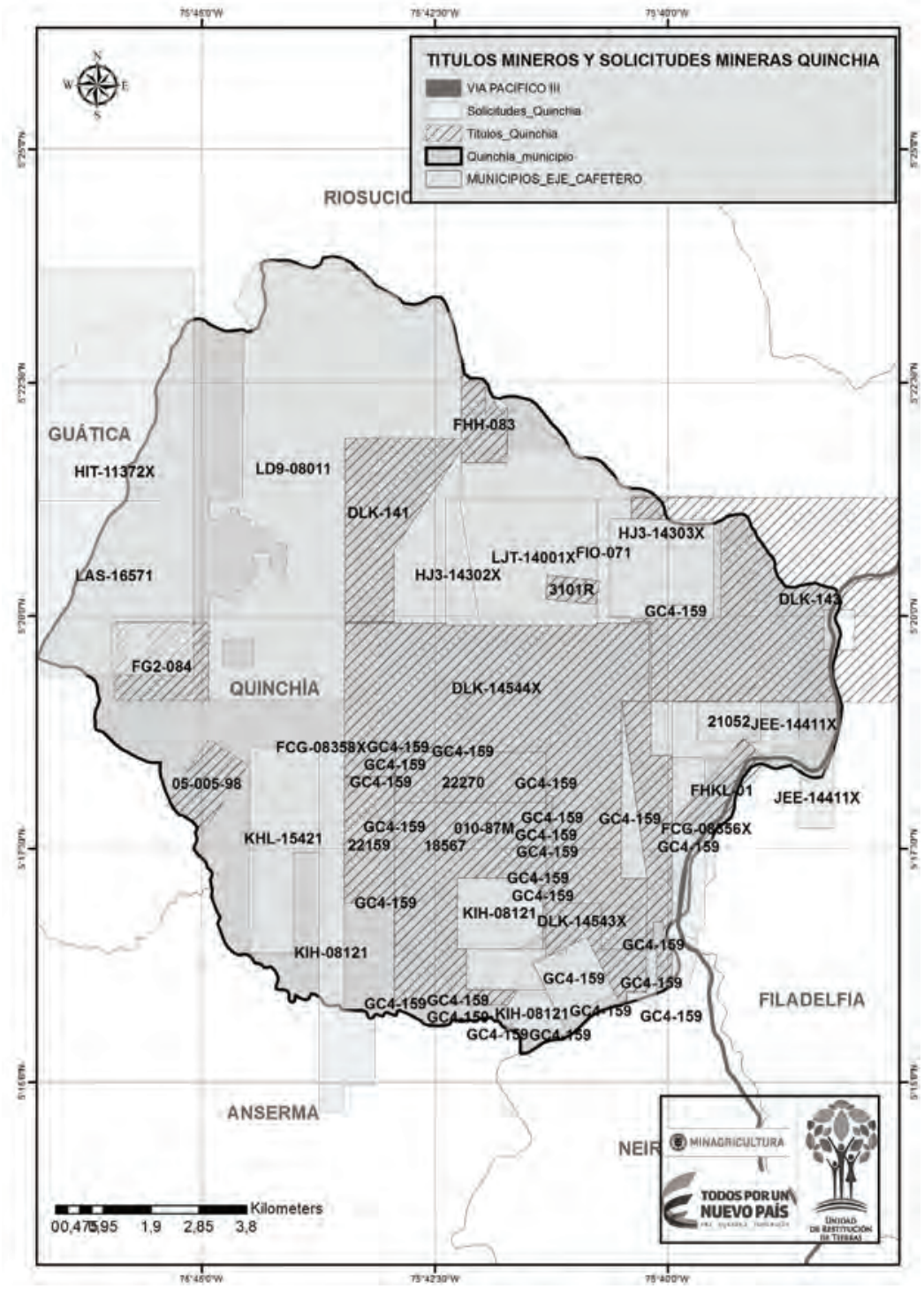

Fuente: Unidad de Restitución de Tierras, septiembre de 2015 
y contratos de concesión abarcan más del $90 \%$ del territorio municipal (Salazar, 2014, p.62) (ver mapa 7).

Mientras tanto, en el proceso electoral del año 2015 fue nombrado alcalde de Quinchía Jorge Alberto Uribe ${ }^{13}$, quien antes estuvo a cargo de la administración del municipio entre los años 2004-2007. Este agente social se comprometió en medios de comunicación periodísticos a "fortalecer a Quinchía como municipio productor agropecuario y minero" (Diario del Otún, 2015).

El Plan de Desarrollo Quinchía Primero (2016-2019) ha establecido el subprograma Fortaleciendo el Sector Agropecuario y Minero para Lograr la Reconciliación. Este plan de desarrollo señala que mediante la Ley 1382 y el Decreto 2715 de 2010 se vienen adelantando procesos de legalización para la minería de hecho, con el acompañamiento y apoyo de la Gobernación de Risaralda (Alcaldía de Quinchía, 2016, p.132).

Pese a las pretensiones plasmadas en dicho plan de desarrollo, a mediados del año 2016, debido a las condiciones de seguridad minero-ambientales, la Agencia Nacional Minera ordenó al mandatario municipal cerrar 40 socavones existentes a orillas del río Cauca. Esta situación generó incertidumbre para más de 300 mineros tradicionales y sus familias, que durante décadas han estado desarrollando la minería de cúbico para su subsistencia en el corregimiento de Irra ${ }^{14}$.

De acuerdo con el líder minero de Irra, Francisco Anduquia:

En relación con el tema de la legalidad y de la problemática alrededor de la minería, existe una incertidumbre porque no se sabe en qué momento

13 Como se visualiza en la página de la Alcaldía de Quinchía, Jorge Alberto Uribe se desempeñó entre 2008 y 2013 como profesional sénior social de la empresa AngloGold Ashanti Colombia S.A.

14 Véase: http://caracol.com.co/emisora/2016/05/15/pereira/1463311546_928321.html 
el gobierno va a tomar medidas drásticas. El concepto que manejamos en Irra es que nuestro trabajo es una minería artesanal, las personas se sienten muy agradecidas con la minería en Irra, incluso con todos los fenómenos que estamos viviendo en el país de movilización, proceso de paz, la minería se ha convertido en una opción de empleo (Entrevista realizada a Francisco Anduquia, 2016).

En respuesta al cierre de las minas ${ }^{15}$ y en defensa de la minería tradicional, se realizó una movilización que contó con la participación de dos mil mineros de Risaralda y Caldas en Irra. "La idea era hacer una marcha pacífica, estamos esperando tener un acercamiento con alcaldes y entidades gubernamentales para hacer mesas de concertación que den soluciones a las necesidades laborales y económicas que tenemos. [...]. En el municipio no hay más ofertas" (Anduquia, citado en El Diario del Otún, 2016). La situación de informalidad de los mineros de Irra y las condiciones de seguridad son aún los principales argumentos de la institucionalidad para ordenar su cierre.

En relación con el desarrollo minero, el Gobierno ha impulsado las vías $4 \mathrm{G}$ - Cuarta Generación- ${ }^{16}$ que se transforman en un atractivo para inversionistas extranjeros, pues significan abaratar costos en el transporte de grandes cargas. Entre los proyectos 4G se destaca la Vía Pacífico III. Esta tiene influencia en el municipio de Quinchía y su infraestructura conectará a Antioquia con Buenaventura y el Eje Cafetero.

La histórica vía que conecta a Manizales y Medellín se desviará antes de llegar a Irra mediante la construcción de dos puentes sobre los ríos Tapias y Cauca, lo cual tendrá incidencia en el centro poblado de Irra, característico por su vocación comercial.

15 El cierre de Minas fue realizado en el sector de Tintina de Anserma (Caldas) y en la vereda Opiramá de Quinchía (Risaralda) (Entrevista realizada a Francisco Anduquia, 2016).

16 Véase Infraestructura minera en la agenda. Disponible en: http://www.dinero. com/pais/articulo/infraestructura-minera/191839 


\section{Sobre las estrategias de posicionamiento corporativo de las empresas mineras}

Sumado a lo anterior, en Quinchía, tras el ingreso de empresas multinacionales en el marco de las políticas nacionales, regionales y locales, se inició una campaña de legitimación corporativa mediante la promesa de realizar una minería sostenible como eje de desarrollo social y económico en el territorio.

De esta manera, para el año 2012, la Batero Gold concentró sus esfuerzos en obtener la licencia social ${ }^{17}$, mediante la adopción de estrategias que buscaban "proporcionar beneficios ambientales, sociales y económicos a largo plazo para la región de Quinchía"18. De acuerdo con la empresa multinacional tales beneficios son:

- Apertura de espacios no utilizados para instalar una unidad médica y dental — suministrada por el hospital local-y un hogar infantil comunitario.

- Reparación y mantenimiento de caminos veredales.

- Apoyo para aumentar el acceso a la electricidad en áreas rurales.

- Suministro de agua potable desde la planta de filtración de la compañía a 38 familias de la comunidad.

- Implementación del programa Fincas con Futuro

17 La Licencia Social para Operar — LSO — se refiere a la aceptación de las compañías mineras y de sus proyectos dentro de las comunidades locales. Información disponible en: http://www.miningfacts.org/Comunidades/Que-es-la-licencia-socialpara-operar-LSO/

18 http://baterogold.com/projects/quinchia-project. Sitio web de la Batero Gold, 2015. 
- Desarrollo de actividades de perforación mediante el cumpliendo de estrictas reglas y regulaciones gubernamentales.

- Apoyo a programas de corte y confección que permiten a las mujeres generar nuevos ingresos a través de la venta de la ropa que fabrican.

Sin embargo, estos programas de acento filantrópico están emparentados con los beneficios corporativos que las compañías multinacionales adquieren mediante la inversión socioambiental:

- La realización de caminos veredales y el aumento en la cobertura de energía eléctrica también se convierten en mejoras empresariales que permiten obtener mayores ventajas para el desarrollo de actividades de exploración y extracción.

- El desarrollo de programas asistencialistas (generación de empleo, programas escolares y disposición de infraestructura, entre otros) tiene como fin alcanzar el aval comunitario, pues esta licencia social permite a las empresas júnior atraer la atención de otros inversionistas extranjeros.

- En contraste con las acciones corporativas ligadas a garantizar el suministro de agua potable a las comunidades locales y el cumplimiento de las normas de perforación, el presidente de la Asociación de Acueductos Comunitarios de Quinchía, Jesús Guevara, señaló -en una carta radicada en 2013 dirigida a la Carder con copia al Ministerio de Ambiente- que las perforaciones realizadas por las empresas Batero Gold y Minera Seafield han ocasionado impactos sobre las fuentes hídricas que abastecen acueductos comunitarios en sus zonas de influencia (Salazar, 2014, p.125).

- Afectación a las dinámicas económicas y socioculturales de las comunidades locales, mediante estrategias de posicionamiento como el programa Fincas con Futuro "que consiste en intercambiar fincas 
de habitantes quinchieños localizados en zonas mineras de la empresa Batero Gold, por fincas adyacentes” (Salazar, 2014, p.120).

A este respecto, Pardo (2014) señala los costos sociales y ambientales que tienen estrategias corporativas como la compra de tierras:

La compra de grandes extensiones de tierra alrededor de los proyectos permite ocultar la contaminación sobre aguas superficiales y subterráneas [...]. A esto se agrega el desplazamiento de familias tras la venta o la expropiación por vía administrativa de sus propiedades, con la consecuente ruptura del tejido social y la sustracción de extensiones de tierra de sus actividades tradicionales como agricultura y ganadería (p.39) ${ }^{19}$.

Entre tanto, la Seafield Resources, ahora Miraflores Compañía Minera S.A.S., reconoce en su página oficial la importancia de la responsabilidad social corporativa en sus proyectos y operaciones.

Nosotros también reconocemos el impacto positivo que podemos lograr sobre las comunidades donde operamos. Seafield desarrolla alianzas con las partes interesadas de la comunidad y su objetivo es ser líder en la responsabilidad social. Nuestra estrategia para ser una compañía responsable de exploración y minería se centra en nuestro compromiso de emplear personal local donde sea posible ${ }^{20}$, avanzando en las iniciativas de la comunidad a través de la financiación y las alianzas constituyendo una estrategia efectiva de gestión ambiental (Página web de la Seafield Resources, 2015).

No obstante, es pertinente mencionar que, tras las negociaciones entre la compañía minera Seafield Resources y 38 integrantes de la Asociación de Mineros de Miraflores, se hizo efectiva la compra de un título de

19 Este mismo documento expone la adquisición de predios por parte de empresas multinacionales (Ver Pardo, 2014, p.39).

20 Por su parte Giovanny Ortiz, quien se ha desempeñado como gerente del proyecto Minera Seafield, señala que el total de personas que laboran para la empresa son 10 personas en Quinchía y 17 en Medellín (Entrevista a Giovany Ortíz, 2016). 
150 hectáreas, por un monto de 6000 millones de pesos (Garcés, 2013; Obando, 2014 citado por Salazar, 2014). Esta situación ha generado conflictos mineros, pues tanto la asociación de Mineros de Miraflores como la Asociación de Barequeros continúan realizando actividades de extracción en el actual proyecto de la empresa multinacional.

En respuesta a este conflicto, la empresa Seafield Resources, mediante la intervención de la Mesa Departamental Minera y el Distrito Minero, propuso, en el año 2013, la subcontratación de la asociación de barequeros en el proyecto de la multinacional alternativa. Este, según Giovany Ortiz ${ }^{21}$, "fue un acuerdo de buena voluntad, pues no se ha firmado nada” (entrevista realizada a Giovany Ortiz, 2016). Sin embargo, la crisis de la empresa generó incertidumbre en los mineros tradicionales, entre otros aspectos, porque esta compañía solicitó acogerse a la Ley 1116 de 2006, concerniente al régimen de insolvencia empresarial.

Así lo señaló Jhonny Garcés, presidente de la Federación de Pequeños Mineros de Risaralda y Caldas, y exconcejal del municipio de Quinchía:

La Seafield ha agotado su presupuesto adquirido a través de deudas en fondos de inversión. Buena parte lo usó para promover sus aparentes "buenas pretensiones”. Se inventó empleos temporales por periodos de tres meses, alardeando tener una planta de 300 empleados. Lo cierto es [...] que no tiene efectivo y tuvo que dar 15,6 millones de acciones a sus funcionarios para que no se fueran y no ha podido pagar ni la primera cuota (\$402 317 dólares canadienses) de su enorme deuda (16,5 millones de dólares canadienses) con RMB Australia Holdings Limited (Garcés, 2014).

Esta situación concluyó con la adquisición de la empresa por parte de la compañía Metminco Limited, tal como lo señala Giovany Ortiz: "La Seafield entró en crisis, la empresa realizó un préstamo y cuando entró

21 Giovany Ortiz se ha desempeñado como gerente del proyecto Seafield en Quinchía. Actualmente es el vicepresidente de Exploración de la Metminco Limited. 
la crisis del oro, la empresa ya no pudo pagar; por tanto, el banco tomó el proyecto y se lo vendió a Metminco Limited” (entrevista realizada a Giovany Ortiz, 2016).

Paralelo a esta situación, y acorde con las orientaciones nacionales, la empresa multinacional viene realizando programas productivos que tienen como fin exhortar a los mineros tradicionales a concentrar los esfuerzos en el desarrollo agrícola.

De esta manera, en la vereda Miraflores, el programa de formalización, más allá de implementar estrategias orientadas al mejoramiento efectivo de las condiciones técnicas, sociales y ambientales de la minería tradicional, busca promover una reconversión de la actividad. Desde esta perspectiva, lo que pretende el programa es estimular el desarrollo de la minería sostenible asociada con las empresas multinacionales que, como se evidencia con la concesión de títulos en zonas de presencia de comunidades indígenas, campesinas y mineras, genera conflictos territoriales.

Es imprescindible anotar que el Plan Nacional de Desarrollo Paz, Equidad y Educación 2014-2018, establece que:

El Estado trabajará para que todos los proyectos mineros independientemente de su clasificación cumplan con las exigencias técnicas, laborales, económicas y ambientales previstas por la ley. En aquellas zonas donde el ejercicio de actividades mineras no sea viable, el Gobierno nacional acompañará a las personas que ejercen la actividad minera en la reconversión laboral hacia actividades productivas viables en esa área (Departamento Nacional de Planeación, 2014, p.194).

De acuerdo con las propuestas gubernamentales señaladas en el Plan Nacional de Desarrollo (2014-2018), en Miraflores se aboga, más que por el establecimiento del programa de formalización, por estrategias tendientes a la reconversión de la minería tradicional. 
Proyectos realizados por la compañía Seafield buscan ofrecer al minero tradicional, en veredas como Miraflores, el aprovechamiento de plántulas de mora y plátano como la principal alternativa de sustento económico. Situación que, según expone el artículo periodístico de Duberney Galvis, integrante del Polo Democrático, se encuentra orientada al abandono de la minería tradicional ${ }^{22}$.

En coherencia con lo anterior, el actual alcalde Jorge Alberto Uribe, señala:

Queremos ver cómo entramos a apoyar a estos mineros que se van a ver en una persecución aterradora. Vamos a sentarnos con la Mesa Nacional Minera, con instancias ambientales y el Estado para buscar una solución, qué ganan con perseguirlos si no hay una solución para ellos. Queremos una propuesta de proyectos de gran envergadura que en vez de minería artesanal se dediquen a otra actividad económica (Diario del Otún, 2015).

Estos esfuerzos por motivar la reconversión de la actividad minera tradicional por otras actividades productivas tienen entre sus propósitos permitir que existan territorios de gran potencial geológico libres de comunidades mineras que impidan el desarrollo de proyectos extractivos multinacionales.

\section{Comunidades indígenas y desarrollo minero multinacional}

De otro lado, en el marco del Convenio 169 de la OIT, la Constitución Política de Colombia de 1991 y el Decreto 1320 de 1998, entre otros instrumentos políticos y normativos, las pretensiones de instalar proyectos minero-extractivos deben estar acompañadas de la consulta previa,

22 Ver Megaminería suena a Gaviria. Disponible en http://www.traslacoladelarata. com/2014/06/24/megamineria-en-risaralda-suena-un-gaviria-trujillo/ 
libre e informada con el fin de proteger los derechos de los pueblos ancestrales que se encuentren en el territorio. De esta manera, el municipio de Quinchía aparece especialmente protegido por esta normativa, ya que posee comunidades indígenas que se encuentran asentadas en cuarenta y cuatro veredas, veinte de ellas con presencia de minería tradicional y multinacional.

Algunos de los territorios quinchianos que deben ser protegidos son, por ejemplo, el corregimiento de Naranjal, donde se encuentra localizada la empresa Batero Gold, pues allí habitan 243 indígenas de la parcialidad emberá karambá distribuidos en las veredas Santa Sofía y La Palma. Además, están presentes 540 indígenas pertenecientes a la parcialidad emberá chamí, localizados en las veredas Yarumal, Cruces, Naranjal y Chorroseco (Ugarte et al., 2013).

Por otra parte, está también el corregimiento de Irra, donde se encuentra localizada la empresa Miraflores Compañía Minera S.A.S., perteneciente Metminco Limited, el cual alberga 792 habitantes indígenas de la parcialidad emberá karambá, distribuidos en las veredas Miraflores, Callao y Mápura. Asimismo, este corregimiento cuenta con 753 habitantes pertenecientes al resguardo Escopetera y Pirza en las veredas Agua Salada, Risaraldita, Ginebra y Sausaguá; y 316 indígenas pertenecientes a la parcialidad emberá chamí, localizados en el centro poblado de Irra y Corozal (Ugarte et al., 2013).

La presencia de riqueza mineral en territorios con comunidades indígenas se traduce en conflictos socioambientales, como los documentados en la investigación Evaluación de la Sustentabilidad Cultural y Ambiental de la Minería Tradicional. Caso de Estudio Corpoare (2014) ${ }^{23}$, que

23 En esta investigación se analizaron los siguientes conflictos: A) conflictos que se configuran por la disputa entre asociaciones mineras tradicionales y empresas multinacionales en territorios con riqueza mineral, B) conflictos relacionados con la existencia de explotaciones mineras tradicionales y multinacionales en territorios de comunidades indígenas o zonas solicitadas por los emberá chamí y emberá 


\section{Mapa 8. Comunidades indígenas, zonas de tradición minera y multinacionales con título de exploración en Naranjal e Irra}

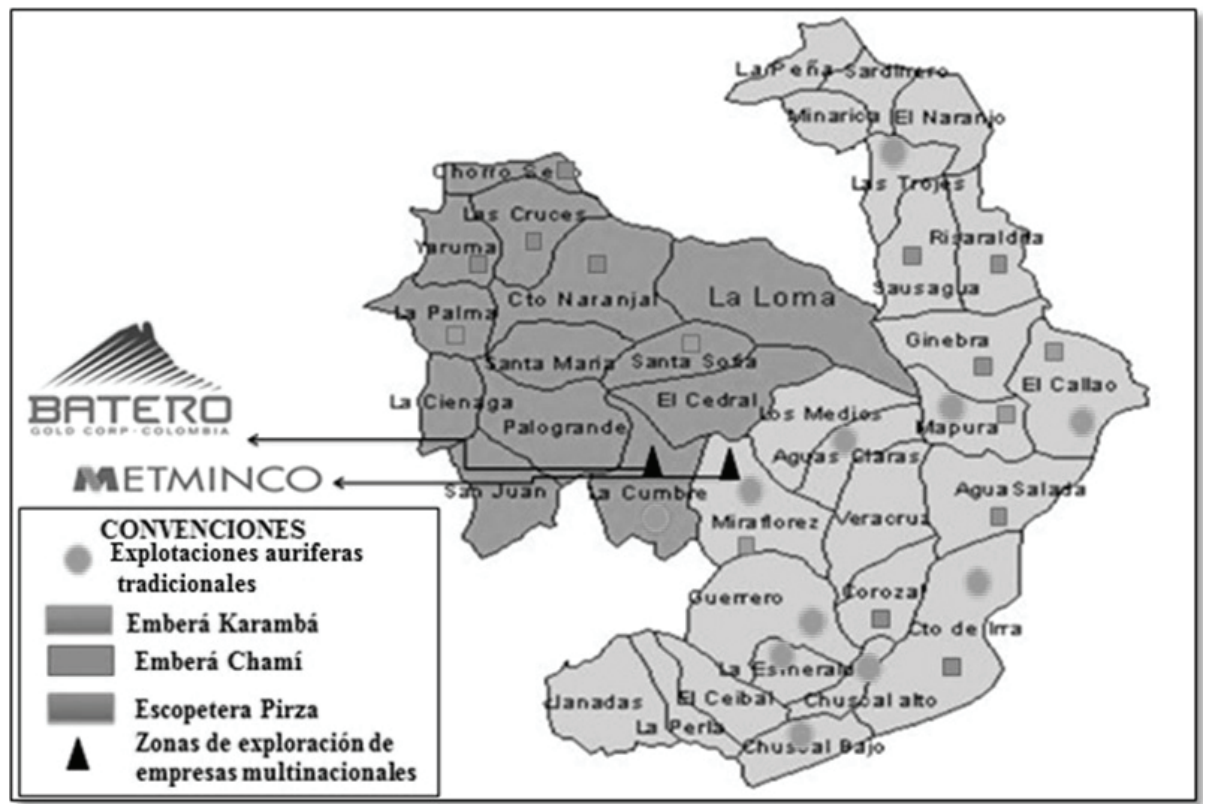

Fuente: Elaborado con base en información primaria y Ugarte et al, 2013

enuncia conflictos asociados a la existencia de explotaciones mineras tradicionales y multinacionales en zonas con parcialidades indígenas (ver mapa 8).

karambá para la constitución de un resguardo indígena, y C) otros conflictos por la apropiación del patrimonio natural entre los que se destaca un precedente sobre la comercialización de 2000 metros cúbicos de agua de consumo humano a la empresa Seafield, la afectación de fuentes hídricas que abastecen acueductos comunitarios y, finalmente, disputas territoriales, entre las que sobresale la reclamación de propiedades en zonas mineras por víctimas de conflicto armado en Colombia (Salazar, 2014). 
Dichos conflictos también están sustentados en las denuncias realizadas en el año 2013 por Gloria Inés Hoyos Hoyos, exgobernadora del resguardo indígena Escopetera y Pirza, y Edith Lucía Taborda, gobernadora de la parcialidad indígena emberá karambá, quienes instauraron una acción de tutela en contra del Ministerio del Interior -Dirección de Consulta Previa- y de la Compañía Minera Seafield S.A.S., con el propósito de suspender las actividades de exploración y explotación por parte de la multinacional en los territorios indígenas ${ }^{24}$.

Durante el año 2015, iniciaron los diálogos con las comunidades emberá chamí y emberá karambá para dar comienzo a la consulta previa, libre e informada. Sin embargo, la empresa multinacional Seafield, ahora Metminco Limted, solo llegó a un acuerdo para la realización de dicha consulta con la comunidad emberá chamí.

Según las exigencias de la comunidad emberá chamí, resultaba imperativo realizar una línea base socioambiental en los territorios indígenas de dicha parcialidad donde se pretendieran desarrollar proyectos mineros, con el fin de identificar posibles impactos. No obstante, una de las principales limitaciones de esta consulta fue la insuficiente información secundaria y técnica para realizar una evaluación confiable y detallada para el mes de diciembre del año 2016, en palabras de Fernando Saldarriaga, profesional en administración ambiental encargado de acompañar el proceso de consulta,

las dificultades que tuvimos fueron a nivel conceptual, metodológico, incluso, las dificultades de no tener herramientas, ni los equipos para realizarlo, por ejemplo, el estudio no consideró análisis de agua y no se lograron hacer los aforos porque no había los recursos económicos, o porque cuando llagaron los recursos ya no alcanzaba el tiempo para poderlo hacer;

24 Ver respuesta a la acción de tutela. Corte Suprema de Justicia (29 de agosto de 2013). Ref. Exp. 11001-02-03-000-2013-01900-00. 
por tanto, está pendiente el análisis de agua y suelos (entrevista realizada a Fernando Saldarriaga, 2016).

Por su parte, debido a la ausencia de un acuerdo entre la parcialidad emberá karambá y la empresa Seafield Resources —ahora Metmico Limited - sobre la ruta metodológica para iniciar la consulta previa, libre e informada y las divergencias en su tiempo de duración, el Ministerio del Interior decidió el 22 de septiembre de 2016 cerrar el proceso ${ }^{25}$; situación que vulneró los derechos constitucionales de la comunidad indígena.

Sin embargo, y pese a la importancia de la consulta previa, libre e informada $^{26}$ para salvaguardar los derechos de las comunidades indígenas, esta, según algunos agentes sociales relacionados con el sector minero y ambiental, no es considerada como un mecanismo que pueda vetar el desarrollo de un proyecto sobre minería. A propósito de esto Martha Pachón comenta: "La consulta previa no es para pedirles permiso a las comunidades indígenas si dejan realizar un proyecto minero. El objetivo de una consulta previa es contar, ahí no se pueden tomar decisiones sobre sí se realiza el proyecto de minería o no" (entrevista realizada a Martha Pachón, 2016). Otro tanto comenta Darwin Hernández: "En términos jurídicos la norma de consulta previa o el instrumento de consulta previa no es para vetar proyectos, sino para garantizar las

25 Ver Acta de cierre de consulta. Disponible en: http://www.mininterior.gov.co/sites/default/files/documentos/ConsultaPrevia/Protocolizaciones/acta_de_cierre_ de_consulta_titulos_mineros_de_interes_de_la_minera_seafield_S.A.S_proy64301-03.pdf

26 La consulta previa tiene por objeto analizar el impacto económico, ambiental, social y cultural que puede ocasionarse a una comunidad indígena o negra por la explotación de recursos naturales dentro de su territorio (Decreto 1320 de 1998). Por su parte, el parágrafo del artículo 330 de la Constitución Política establece: "La explotación de los recursos naturales en los territorios indígenas se hará sin desmedro de la integridad cultural, social y económica de las comunidades indígenas. En las decisiones que se adopten respecto de dicha explotación el Gobierno propiciará la participación de los representantes de las respectivas comunidades". 
condiciones económicas y culturales de la comunidad allá asentada" (entrevista realizada a Darwin Hernández, 2016) ${ }^{27}$.

Empero, el gobernador de la comunidad emberá chamí, Arley Guapacha, señala que la consulta, previa, libre e informada:

ha sido una oportunidad para conocer el territorio y tener argumentos para manifestarle a estas empresas que no es viable hacer mega-minería o rechazar su presencia en el municipio, pero [sic] con razones de peso, como el tema arqueológico, ambiental, demográfico, social, soberanía alimentaria; con reafirmaciones técnicas, con la comunidad y generando conciencia (entrevista realizada a Arley Guapacha, 2016).

Paralelo al proceso con las comunidades indígenas en Quinchía, se está considerando la posibilidad de realizar una consulta popular para determinar si se avala o no el desarrollo de proyectos multinacionales en el territorio (entrevista Arley Guapacha, 2016; Bedoya, 2016). Mientras tanto, en el municipio continúa vigente la minería transnacional en oposición a las comunidades mineras, campesinas e indígenas.

En Quinchía se ha afianzado, mediante diferentes planes de desarrollo nacional, regional y local, el interés de impulsar una minería ambiental y socialmente responsable como el eje del desarrollo sostenible. Sin embargo, dicho interés representa un manto discursivo que legitima la presencia de empresas transnacionales en contraposición a los intereses de las comunidades locales de un municipio de larga tradición minera, diversidad cultural y riqueza natural.

27 Martha Pachón fue directora del Distrito Minero de Risaralda, actualmente dirige el programa de Responsabilidad Social relacionado, entre otras cosas, con los asuntos mineros del departamento. Por su parte, Darwin Hernández, docente de la Facultad de Ciencias Ambientales de la Universidad Tecnológica de Pereira, fue el director del Área Ambiental en la Seafield Resources entre octubre de 2011 y 2013, y director de Sostenibilidad entre 2013 y 2015. 


\section{Tabla 2. Estrategias de gestión ambiental frente al desarrollo minero-extractivista en Quinchía}

\section{Escala \\ Estrategias de Gestión Ambiental Territorial —EGAT-}

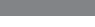
Internacional
Estrategias de Gestión Ambiental Sectorial -EGAS-

\section{Acuerdos internacionales sobre} desarrollo minero mundial

- Iniciativas para el desarrollo minero responsable. Organización para la Cooperación y Desarrollo Económico OCDE-

- Estándares de la Iniciativa para la Transparencia de las Industrias Extractivas -EITI-. Organismos multilaterales

- Responsabilidad social y ambiental en el desarrollo minero. Consejo Internacional de Minería y Metales -ICMM-

\section{Políticas internacionales extractivas}

- Proyecto Mesoamérica para la Integración. Mecanismo de diálogo político de alto nivel para construir consensos y articular esfuerzos de cooperación entre diez países: Belice, Colombia, Costa Rica, El Salvador, Guatemala, Honduras, México, Nicaragua Panamá y República Dominicana.

- Desarrollo y Proyecto de Integración de la Infraestructura Regional Suramericana -IIRSA-. Iniciativa creada por las doce repúblicas que integran la Unión de Naciones Suramericanas

- El Convenio 169 de la oit, artículo 06, establece que los gobiernos deberán realizar la consulta a los pueblos indígenas cada vez que se prevean medidas susceptibles de afectarles directamente.
Nacional
Desarrollo normativo

- Ley 685 de 2001. Código de Minas

- Decreto 0276 de 17 de febrero de 2015. Registro Único de Comercializadores Mineros - RUCOM-

- Decreto 2041 de 2014. Licencias ambientales exprés

Desarrollo programático

- Plan Nacional de Desarrollo Hacia un Estado Comunitario (2002-2006). Impulso a exploración y explotación de hidrocarburos y minería a través de eficiencia sectorial, infraestructura para transporte de minerales, desarrollo de proyectos productivos y promoción de la sostenibilidad ambiental.

- Plan Desarrollo Minero (2002-2006). Ejes estratégicos: 1) fortalecer la exploración del territorio, 2) implementar el sistema de información minero, 3) au-
Desarrollo normativo

- Ley 685 de 2001. Código de Minas.

- Ley 685 de 2001, artículo 31. Áreas de Reserva Especial Minera.

- Resoluciones $\mathrm{N}^{\circ} 180241$ y 0045 de 2012 y la Resolución N 429 de 2013 del Ministerio de Minas y Energía, y la Agencia Nacional de Minería - ANM*- Declaratoria de Áreas Estratégicas Mineras.

- Decreto 0934 de 2013, que reglamenta el artículo 37 de la Ley 685 de 2001. Competencias a instituciones para establecer zonas excluidas y restringidas de minería en contextos municipales*.

- Ley 1450 de 2011 y 20 de la Ley 1753 de 2015, artículo 108. Creación y ampliación de la figura Áreas de Reserva Estratégicas Mineras - $\mathrm{AEM}^{*}$ - 
Nacional (continuación) mentar eficiencia de la autoridad minera, 4) articular la actividad minera, 5) avanzar en la legalización minera, 6) ampliar la infraestructura, 7) promover cadenas productivas, y 8) sostenibilidad ambiental de la actividad.

- Plan Nacional de Desarrollo Estado Comunitario: Desarrollo para Todos (2006-2010). Promover un aumento en la productividad de las explotaciones mineras legales mediante el fomento a la asociación de mineros en distritos, el ajuste al Código de Minas, una reforma institucional y el mejoramiento de la infraestructura, entre otras.

- Colombia País Minero. Plan Nacional para el Desarrollo Minero Visión al año 2019. Planificación hacia la competitividad de la minería.

- Plan Nacional de Desarrollo Minero (2007-2010). Líneas de acción: 1) estrategias para el crecimiento del sector, 2) estrategias para el desarrollo de las regiones mineras, y 3 ) política ambiental para la minería.

- Políticas: Administración del Recurso Minero (2006), Mejoramiento de la Productividad y Competitividad del Sector (2008), Promoción del País Minero, Formalización Minera (2014) y Seguridad Minera.

- Plan Nacional de Desarrollo Prosperidad para Todos (2010-2014). Locomotora minero-energética como eje para "el crecimiento y la generación de desarrollo en el país". Para tal fin se propone crear un marco institucional sólido: desarrollar estrategias para aumentar la productividad y formalizar y mejorar la seguridad del sector minero; consolidar el Sistema Nacional de Información Minero (SI Minero), y diseñar esquemas de transferencia tecnológica.

- Plan Nacional de Desarrollo Todos por un Nuevo País. Paz, Equidad y Educa-
- Ley 1753 de 2015, artículos 49, 50 (parcial), 51 y 52 (parcial), que desarrollan el Sistema de Proyectos de Interés Nacional y Estratégico - Pines-*.

- Ley 1753 de 2015, parágrafo del artículo 173 , que regula actividades extractivas en ecosistemas de páramo*

- Decreto 2041 de 2014. Licencias ambientales exprés.

- Decreto 2691 de 2014. Medidas para que autoridades locales municipales determinen con estudios técnicos zonas de importancia ecosistémica que deben ser protegidas de la minería e incorporadas en sus planes de ordenamiento territorial*.

- Distritos mineros definidos por la Unidad de Planeación Minero Energética en el documento Distritos Mineros: Exportaciones e infraestructura de transporte (2005)

- Consulta Previa Libre e Informada, artículo 246 y artículo 330 parágrafo de la Constitución Política de Colombia. Ley 21 de 1991 por medio del cual se aprueba en Colombia el Convenio 169 de la OIT. Decreto 1320 de 1998, por el cual se reglamenta la consulta previa con las comunidades indígenas y negras para la explotación de los recursos naturales dentro de su territorio. 


\section{Escala \\ Estrategias de Gestión Ambiental Territorial —EGAT-}

Nacional

(continuación)
Estrategias de Gestión Ambiental Sectorial -EGAS- ción (2014-2018). Eje estratégico: “consolidar al sector minero con responsabilidad social y ambiental, como impulsor del desarrollo sostenible del país". Para tal fin propone fomentar: 1) el desarrollo económico del sector minero, 2) propender por una actividad minera con responsabilidad ambiental, y 3) potenciar las oportunidades (inclusión social).

- Política Minera Colombiana- Bases para la Minería del Futuro (Resolución $\mathrm{N}^{\circ} 4$ 0391 de 20 de abril de 2016) un documento que recoge las diferentes políticas y lineamientos existentes en el país, transformándose en la política minera única integral de Colombia.
Regional

\section{Desarrollo programático}

- Plan Departamental Risaralda Desarrollo con Rostro Humano y Social en Igualdad de Oportunidades (2001-2003). Organización del sector minero, apoyo para la industrialización de la minería y promoción de su sostenibilidad.

- Plan de Desarrollo Departamental Risaralda, Sentimiento de Todos (2008-2011). Programa La Minería, Factor Social en el Desarrollo Económico, que busca incentivar, la productividad y competitividad hacia el crecimiento sostenible.

- Plan de Desarrollo Risaralda Unida, Incluyente y con Resultados (2012-2015). Programa Minería Socialmente Responsable y Sostenibilidad Socioambiental, para fortalecer las empresas del sector minero mediante asociatividad, legalidad y responsabilidad jurídica.

- Plan de Desarrollo Risaralda Verde y Emprendedora (2016-2019), enfocado en "fortalecer técnica, administrativa y financieramente la cadena productiva del sector minero del departamento de Risaralda".

\section{Desarrollo normativo}

- Distrito Minero de Risaralda, integrado por los municipios de Mistrató, Pueblo Rico, Quinchía, Apía y La Virginia, definido por la Unidad de Planeación Minero Energética.

- Programa de Responsabilidad Social de la Secretaría de Desarrollo Económico de la Gobernación de Risaralda. Busca asesorar, apoyar, capacitar y brindar asistencia técnica a todo el sector minero en el departamento. 
Desarrollo programático

- Plan de Desarrollo de Quinchía. En Marcha Hacia un Futuro Mejor (20012003). Enfoque en actividades de asistencia técnica, comercialización y mitigación de impactos ambientales.

- Plan de Desarrollo de Quinchía. Una Alcaldía con Compromiso Social (20042007). Enfocado en potenciar el desarrollo minero desde una perspectiva ambientalmente sostenible.

- Plan de Desarrollo Todos por Quinchía con Acción y Decisión (2008-2011), orientado a fortalecer el sector minero mediante cooperativismo, asistencia a pequeños mineros y mejoramiento de condiciones socioambientales.

- Plan de Desarrollo Quinchía para Todos (2012-2015), que ofreció garantías para explotación del suelo rural, como el estímulo a la actividad minera desarrollada por pequeños y grandes mineros. También se propuso realizar el Plan Ambiental Minero, sin éxito.

- Plan de Desarrollo Quinchía Primero (2016-2019). Pretende fomentar el desarrollo social y ambientalmente sostenible de la actividad minera, mediante el cumplimiento de políticas de responsabilidad social empresarial y la implementación del Plan Ambiental Minero. Propende por: 1) buscar alternativas de proyectos productivos, técnicos y tecnológicos en la minería, 2) realizar asistencia técnica, jurídica y económica al minero tradicional.

\section{Desarrollo normativo}

- Plan Básico de Ordenamiento Territorial de Quinchía - Рвот- (2000), artículo 36. Usos en la Zona de Actividad Minera. En este se establece que para la explotación racional y sostenible del sector minero debe haber medidas ambientales y la consolidación de un plan ambiental minero.

- Áreas de Reserva Especial Minera, Ley 685 de 2001, artículo 31. Corporación Área de Reserva Especial Minera - Corporare- y Cooperativa Productora de Carbón en el municipio de Quinchía -Coocarboquin-

- Vía Pacífico III impulsada por el Gobierno Nacional desde la Agencia Nacional de Infraestructura.

\section{Mecanismos de posicionamiento corporativo}

- Estrategias de legitimación corporativa impulsadas por las empresas mineras con presencia en el municipio de Quinchía: apoyos escolares, inversión en programas de capacitación en confección y orfebrería, mejoramiento o reparación de caminos veredales, entre otros.

- Compra de predios en zonas con potencial minero por parte de empresas mineras.

- Promoción de la reconversión de la minería tradicional en otras actividades productivas motivada por empresas mineras y agentes institucionales.

- Consulta previa, libre e informada del Ministerio del Interior a las comunidades indígenas emberá karambá y emberá chamí como requisito necesario para realizar actividades de exploración de la empresa Seafield Resources. 


\section{Estrategias de gestión ambiental con incidencia en el desarrollo minero extractivista en el municipio de Quinchía}

Después de revisar el estado del arte de la minería en Colombia en detalle, y partiendo del concepto establecido por las estrategias de gestión ambiental (p. 3), en los corregimientos de Naranjal e Irra, se encontraron modos de operación en diversas escalas con manifestaciones territoriales, determinados por decisiones o acciones que pretenden atribuir a ciertas zonas del territorio énfasis en temas mineros que las diferencien de otras áreas; además, se encuentran también estrategias con expresiones sectoriales, entendidas como intervenciones aplicables al sistema productivo minero.

Ambos grupos de estrategias, tanto los de gestión ambiental sectorial como los de tipo territorial, se concretan principalmente en marcos normativos (políticas, leyes, decretos y acuerdos) y programáticos (planes de desarrollo, programas, proyectos y actividades), así como en acciones corporativas (ver tabla 2).

\section{Reflexiones finales}

Colombia ha concentrado sus esfuerzos en instaurar un modelo de desarrollo que responda a las demandas del mercado internacional. Para tal efecto, diversos agentes gubernamentales promueven la construcción o adecuación de agendas políticas que ofertan, mediante ventajas normativas y económicas, el patrimonio natural y minero de la nación ${ }^{28}$.

Las zonas rurales son transformadas en territorios estratégicos para impulsar apuestas productivas y competitivas que privilegian proyectos

28 Entre "mayo de 2000 y abril de 2005 el número de títulos mineros se incrementó en un $61 \%$ al pasar de 3770 a 6078 . A 31 de diciembre de 2010, el número de títulos inscritos en el Registro Minero Nacional fue de 9011, cifra que representa un incremento del $48 \%$ con respecto a abril de 2005" (Ponce, 2012, p.39). 
extractivos mineros. En este contexto de reprimarización de la economía, el patrimonio natural de los territorios rurales se convierte en uno de los pilares esenciales para las apuestas productivas de diversos agentes gubernamentales y privados de la nación.

En coherencia con estos intereses nacionales, desde finales del siglo xx, Colombia ha impulsado el desarrollo minero-energético mediante diferentes estrategias de gestión ambiental (políticas, planes de desarrollo, leyes, programas, decretos, acuerdos, proyectos, acciones) que, en su mayoría, configuran el interés de impulsar una minería sostenible como eje del desarrollo económico del país. So pretexto del crecimiento económico, se promueve la atracción de agentes transnacionales o compañías extractivas ${ }^{29}$ con lógicas discursivas asociadas a la responsabilidad social y ambiental, que establecen sus estrategias corporativas de control del patrimonio natural y minero de la nación para obtener sus beneficios económicos.

Esta lógica del desarrollo con incidencia en el campo colombiano configura diversos conflictos socioambientales que se suman a problemáticas como la inequitativa distribución de la tierra. De acuerdo con algunos expertos nacionales en el tema (Machado, 2009; Estrada, 2015; Fajardo, 2015 y Vega, 2015, entre otros), la tenencia de la tierra es una de las causas estructurales del conflicto político, social y armado; sin embargo, pese a ello, la idea de una reforma rural integral ha sido relegada y postergada en las agendas gubernamentales, como en el actual Acuerdo de Paz. En contraste, se legitima, sin voluntad real de cambio, el desarrollo como fuerza supuestamente útil para superar la pobreza y establecer mejoras en las condiciones sociales del campo.

En este contexto, frente al interés de posicionar el extractivismo minero, transnacionales como la empresa Miraflores Compañía Minera

29 Para el año 2010, Colombia ya contaba con 34 compañías que planeaban emprender trabajos de exploración, de las cuales 22 eran canadienses (Weitzner, 2012, p.12). 
S.A.S. (perteneciente a Metminco Limited) y Batero Gold se instalan en territorios como Quinchía - municipio inmerso en disputas territoriales históricas-, bajo la promesa de mejorar el bienestar social, económico y ambiental en las zonas de influencia de sus proyectos extractivos. No obstante, estos mecanismos de control territorial desplegados por las empresas multinacionales hacia el siglo XXI se enfrentan con los intereses de las comunidades locales ${ }^{30}$ de un municipio con tradición minera, diversidad cultural y riqueza natural.

Finalmente, conviene reiterar que las zonas rurales albergan distintos problemas que se han configurado históricamente (PNUD, 2011). En el marco de las disputas territoriales y desde la perspectiva de las nuevas lógicas del mercado, lo rural, un espacio vital relegado, ha cobrado relevancia a escala planetaria, pues se entiende como un territorio provisto de riquezas naturales y materias primas, que, bajo la óptica del desarrollo, solo cobra valor si es útil en un escenario de productividad y crecimiento económico.

No obstante, la importancia de lo rural radica no en su potencial de crecimiento y desarrollo, si no en que es un contexto de intercambios socioculturales, portador de patrimonio natural y soporte de las actividades económicas de los pobladores rurales, quienes apelan a la construcción de un nuevo campo colombiano, como es el caso de Quinchía, territorio de gran valor cultural y de larga tradición agrícola y minera en el departamento de Risaralda.

\section{Agradecimientos}

Expreso mis más sinceros agradecimientos a todos aquellos que, de manera directa e indirecta, contribuyeron a la realización de este do-

30 Es importante destacar a las consultas populares que le han dicho NO al desarrollo minero-extractivo en los municipios Piedras y Cajamarca (Tolima), Tauramena (Casanare) Cumaral (Meta), Pijao (Quindío), Arbeláez y Cabrera (Cundinamarca) y Jesús María (Santander). 
cumento. A los morados del municipio de Quinchía y a los integrantes de la línea de investigación en Estudios Socioculturales y Problemática Ambiental, adscrita al grupo de investigación Gestión en Cultura y Educación Ambiental de la Facultad de Ciencias Ambientales de la Universidad Tecnológica de Pereira. A todos ellos infinitas gracias.

\section{Referencias}

Fuentes primarias

Anduquia, Francisco (18 de agosto de 2016). Entrevista de la Línea de Investigación Estudios Socioculturales y Problemática Ambiental (IESPA) [Audio]. Entrevista a líder minero de Irra. Archivo IESPA, Pereira.

Guapacha, Arley (02 de noviembre de 2016). Entrevista de la Línea de Investigación Estudios Socioculturales y Problemática Ambiental (IESPA) [Audio]. Entrevista a Gobernador de la comunidad indígena emberá chamí de Quinchía. Archivo IESPA, Pereira.

Hernández, Darwin (13 de julio de 2016). Entrevista de la Línea de Investigación Estudios Socioculturales y Problemática Ambiental (IESPA) [Audio]. Entrevista a exfuncionario de la empresa Seafield Resources. Archivo IESPA, Pereira.

Obando, Sonier (23 de octubre de 2014). Entrevista de Yuliana Salazar Duque. [Audio]. Entrevista a integrante de la Corporación Área de Reserva Especial Minera - Corpoare- Archivo Yuliana Salazar Duque, Pereira.

Ortíz, Giovany (22 de noviembre 2016). Entrevista de Línea de Investigación Estudios Socioculturales y Problemática Ambiental (IESPA) [Audio]. Entrevista a vicepresidente de exploración de la Seafield Resources, ahora Metminco Limited en el municipio de Quinchía. Archivo IESPA, Pereira.

Pachón, Martha (13 de julio de 2016). Entrevista de la Línea de Investigación Estudios Socioculturales y Problemática Ambiental (IESPA) [Audio]. Entrevista a exdirectora del Distrito Minero de Risaralda. Archivo IESPA, Pereira.

Saldarriaga, Fernando (23 de noviembre de 2016). Entrevista de la Línea de Investigación Estudios Socioculturales y Problemática Ambiental (IESPA) [Audio]. Entrevista a administrador ambiental contratado para apoyar el 
proceso de consulta, previa, libre e informada realizada con la comunidad indígena emberá chamí en el municipio de Quinchía. Archivo IESPA, Pereira.

Fuentes académicas

Arias, Carolina (2013) ¿Neo-extractivismo o desarrollo local? Conflictos territoriales y patrimoniales en el pueblo minero de Marmato (Colombia) (Tesis de maestría). Recuperado de www.iespautp.tk

Cardona, Alfredo (1989). Quinchía mestizo. Pereira: Ed. Fondo Editorial.

Cubillos, León; Tapasco, Lindelia; Arias, Carolina y Salazar, Yuliana (2017). Análisis comparativo de los procesos interculturales de construcción territorial agrícola y minera en el municipio de Quinchía. Casos de Estudio Corregimientos de Naranjal e Irra. Pereira: IESPA.

Estrada, Jairo (2015). Acumulación capitalista, dominación de clase y rebelión armada. Elementos para una interpretación histórica del conflicto social y armado. Bogotá: Gentes del Común.

Fajardo, Darío (2015). Estudio sobre los orígenes del conflicto social armado, razones de su persistencia y sus efectos más profundos en la sociedad colombiana. Bogotá: Gentes del Común.

Fierro, Julio (2012). Políticas mineras en Colombia. Bogotá: ILSA Instituto Latinoamericano para una sociedad y un derecho alternativos

Gudynas, Eduardo (2011). Desarrollo y sustentabilidad ambiental: Diversidad de posturas, tensiones persistentes. En Alberto Matarán Ruíz y Fernando López Castellano (Eds.). La Tierra no es muda: diálogos entre el desarrollo sostenible y el postdesarrollo.

Guhl Nannetti, Ernesto y Leyva, Pablo (2015). La gestión ambiental en Colombia, 1994-2014: ¿un esfuerzo insostenible? Bogotá: Foro Nacional Ambiental.

Machado, Absalón. (2009). La Reforma Rural, una deuda social y política. Bogotá: Universidad Nacional de Colombia.

Muriel, Rafael Darío (2006). Gestión Ambiental. Idea Sostenible, 3(3). Recuperado de http://www.ficad.org/lecturas/lectura_uno_primera_unidad_errss.pdf 
Pardo, Katherine y Salazar, Eliana (2013). Minería, Medio Ambiente y Paisaje Cultura Cafetero en el Municipio de Quinchía, Risaralda: Un reto hacia la sustentabilidad (Tesis de pregrado). Recuperado de http://repositorio.utp. edu.co/dspace/bitstream/11059/3667/1/3637P226.pd

Pardo, Luis Álvaro (2014). Una política integral minera desde la perspectiva de un sistema complejo: hacia un modelo alternativo. En Contraloría General de la República (Ed.) Minería en Colombia: Daños Ecológicos y Socioeconómicos y Consideraciones sobre un Modelo Minero Alternativo.

Parra, Orlando (2007). Pasado y presente de la violencia y la paz en QuinchíaColombia. Bogotá: Pontificia Universidad Javeriana.

Ponce, Álvaro (2012). ¿Cuál locomotora? El desalentador panorama de la minería en Colombia. Bogotá: Debate.

Salazar, Yuliana (2014). Evaluación de la sustentabilidad cultural y ambiental de la minería tradicional de Quinchía. Caso de Estudio Corporación Área de Reserva Especial Minera, Corpoare. Pereira: Universidad Tecnológica de Pereira. Recuperado de http://www.iespautp.tk/

Sánchez, Gonzalo (1983). Bandoleros, gamonales y campesinos: El caso de la violencia en Colombia. Bogotá: El Áncora Editores.

Solano, Aldemar (2011). Boleta de Captura. Bogotá.

Ugarte, Alejandro; Largo, Merardo y Uribe, Fernando. (2013). Historia de Guacuma. Quinchía Risaralda. Pereira: Servimpresos Publicidad.

Vega, Renán (2015). La dimensión internacional del conflicto social y armado en Colombia. Injerencia de los Estados Unidos, contrainsurgencia y terrorismo de Estado. Bogotá: Gentes del Común.

Weitzner, Viviane (2012). Rendición de cuentas de las compañías extractivas en Colombia: una evaluación de los instrumentos de responsabilidad social empresarial (RSE) a la luz de los derechos de los indígenas y los afrodescendientes. Bogotá: The North-South Institute.

Fuentes institucionales

Agencia Nacional de Minería (2013). Agencia Nacional de Minería declara primera área de reserva especial. 
Agencia Nacional de Minería (2013). Decreto 0934 del 9 de mayo de 2013. Por medio del cual se reglamenta el artículo 37 de la Ley 685 de 2001.

Agencia Nacional de Minería (2015). Decreto 0276 de 17 de febrero de 2015. Por medio del cual se adoptan medidas relacionadas con el Registro Único de Comercializadores Mineros (Rucom).

Alcaldía Municipal de Quinchía (1998). Plan de Desarrollo Municipal (19982000). Un pacto por Quinchía.

Alcaldía Municipal de Quinchía (2001). Plan de Desarrollo Municipal (20012003). En marcha hacia un futuro mejor.

Alcaldía Municipal de Quinchía (2004a). Plan de Desarrollo Municipal (20042007). Una alcaldía con compromiso social.

Alcaldía Municipal de Quinchía (2008). Plan de Desarrollo Municipal (20082011). Todos por Quinchía con acción y decisión.

Alcaldía Municipal de Quinchía (2012a). Plan de Desarrollo Municipal (20122015). Quinchía para todos y todas.

Alcaldía Municipal de Quinchía (2012b). Plan Territorial de Salud (2012-2015). Un pacto por Quinchía.

Alcaldía Municipal de Quinchía (2016). Plan de Desarrollo Municipal (20162019). Quinchía primero.

Catastro Minero Colombiano (2010). Títulos y solicitudes mineras en el Departamento de Risaralda año 2010.

Congreso de la República de Colombia (2001). Ley 685 de 2001. Por la cual se expide el Código de Minas y se dictan otras disposiciones. Bogotá.

Congreso de la República de Colombia (2006). Ley 1116 de 2006. Por la cual se establece el régimen de insolvencia empresarial en la república de Colombia y se dictan otras disposiciones. Bogotá.

Congreso de la República de Colombia (2011). Ley 1450 de 2011. Por la cual se expide el Plan Nacional de Desarrollo, 2010-2014. Bogotá. 
Congreso de la República de Colombia (2015). Ley 1753 de 2015. Por la cual se expide el Plan Nacional de Desarrollo 2014-2018 Todos por un nuevo país. Bogotá.

Corte Constitucional (2015). Sentencia T-766/15. Derecho a la consulta previa de comunidades afrodescendientes en áreas estratégicas mineras. Bogotá.

Corte Constitucional (2016). Sentencia C-035/16. Normas sobre creación y ampliación de Áreas de Reservas Estratégicas Mineras. Bogotá.

Corte Constitucional (2016). Sentencia C-273/16. Prohibición legal a las autoridades regionales, locales o seccionales para establecer que zonas del territorio quedan excluidas de manera permanente o temporal de actividad minera. Bogotá.

Departamento Administrativo Nacional de Estadística (Dane) (2005). Censo General de Quinchía (Risaralda) 2005. Bogotá.

Departamento Nacional de Planeación (1991). Plan Nacional de Desarrollo 1991-1994. La Revolución Pacífica. Bogotá.

Departamento Nacional de Planeación (2002). Plan Nacional de Desarrollo 2002-2006. Hacia un Estado comunitario. Bogotá.

Departamento Nacional de Planeación (2005). Ficha de caracterización municipio de Quinchía.

Departamento Nacional de Planeación (2006). Plan Nacional de Desarrollo 2006-2010. Estado comunitario desarrollo para todos. Bogotá.

Departamento Nacional de Planeación (2010). Plan Nacional de Desarrollo 2010-2014. Prosperidad para Todos. Bogotá.

Departamento Nacional de Planeación (2014). Plan Nacional de Desarrollo 2014-2018. Todos por un nuevo país. Paz, equidad y educación. Bogotá.

Gobernación de Risaralda (2001). Plan de Desarrollo Departamental (20012003). Risaralda desarrollo con rostro humano y social en igualdad de oportunidades.

Gobernación de Risaralda (2008). Plan de Desarrollo Departamental (20082011). Risaralda, Sentimiento de Todos. 
Gobernación de Risaralda (2010). Gobernador hizo apertura oficial del Distrito Minero de Risaralda [Comunicado de prensa].

Gobernación de Risaralda (2012). Plan de Desarrollo Departamental (20122015). Risaralda: unida, incluyente y con resultados.

Gobernación de Risaralda (2016). Plan de Desarrollo Departamental (20162019). Risaralda Verde y Emprendedora.

Ministerio de Ambiente, Vivienda y Desarrollo Territorial (s. f.). Instrumentos de política, normativos, financieros, técnicos, administrativos de educación y participación (2007-2009). Bogotá. Recuperado de https://www.cortolima.gov.co/SIGAM/gen/g2.htm.

Ministerio de Minas y Energía (2006). Política Administración del Recurso Minero. Bogotá.

Ministerio de Minas y Energía (2006). Promoción del país minero. Bogotá.

Ministerio de Minas y Energía (2008). Política mejoramiento de la productividad y competitividad del sector. Bogotá.

Ministerio de Minas y Energía (2011). Política de Seguridad Minera. Bogotá.

Ministerio de Minas y Energía (2012). Resolución 0045 de 20 de junio de 2012. Por la cual se declaran y delimitan unas Áreas Estratégicas Mineras y se adoptan otras determinaciones. Bogotá.

Ministerio de Minas y Energía (2012). Resolución 180241 de 24 de febrero de 2012. Por la cual se declaran y delimitan unas Áreas Estratégicas Mineras y se adoptan otras determinaciones.

Ministerio de Minas y Energía (2014). Política nacional para la formalización de la minería en Colombia. Bogotá.

Ministerio de Minas y Energía (2016). La política minera colombiana. Bases para la Minería del Futuro. Bogotá.

OCDE (2013). Líneas directrices de la OCDE para empresas multinacionales. OECD Publishing. http://dx.doi.org/10.1787/9789264202436-es

Organización de las Naciones Unidas (1987). Comisión Brundtland: Nuestro futuro Común. 
PNUD (2011). Colombia rural. Razones para la esperanza. Informe Nacional de Desarrollo. Humano 2011. Bogotá: INDH-PNUD.

Presidencia de la República de Colombia (1988). Decreto 2655 de 1988. Por el cual se expide el Código de Minas. Bogotá.

Presidencia de la República de Colombia (2003). Política de Defensa y Seguridad Democrática. Bogotá.

Presidencia de la República de Colombia (2014). Promoción del Decreto 2041 de 2014. Por el cual se reglamenta el Título VIII de la Ley 99 de 1993 sobre licencias ambientales.

Presidente de la República de Colombia (2014). El Decreto 2691 de 23 de diciembre de 2014. Por el cual se reglamenta el artículo 37 de la Ley 685 de 2001.

Unidad de Planeación Minero Energética (2002). Plan de Desarrollo Minero (2002-2006). Bogotá.

Unidad de Planeación Minero Energética (2006). Colombia país minero. Plan nacional para el desarrollo minero visión al año 2019. Bogotá.

Unidad de Planeación Minero Energética (2007). Plan Nacional de Desarrollo Minero (2007-2010). Gestión Pública para Propiciar la Actividad Minera. Bogotá.

Unidad para la Atención y Reparación Integral a las Victimas (2013). Informe Nacional de Desplazamiento Forzado en Colombia 1985-2012. Bogotá.

Revistas y periódicos

Bedoya, Stefanía (30 de agosto de 2016). Quinchía prepara consulta popular sobre megaminería. El Diario del Otún. Recuperado de http://www. eldiario.com.co/seccion/RISARALDA/quinch-a-prepara-consulta-popularsobre-megaminer-a-1608.html

El Diario del Otún (11 de diciembre 2015). Unión de municipios para revisar problemática de minería. El Diario del Otún. Recuperado de http://www. eldiario.com.co/seccion/POL \% C3 \% 8DTICA/uni-n-de-municipios-pararevisar-problem-tica-de-miner-a1512.html?score $=4 \& I D=146057$

El Diario del Otún (14 de junio de 2016). Concejales de Quinchía se unieron a los mineros. El Diario del Otún. Recuperado de http://www.eldiario. 
com.co/seccion/RISARALDA/concejales-de-quinch-a-se-unieron-a-los-mineros-1606.html? score $=2 \& I D=155072$

Galvis, Duberney (24 de junio de 2014) Megaminería en Risaralda: suena un Gaviria Trujillo. Tras la cola de la rata. Recuperado de http://www.traslacoladelarata.com/2014/06/24/megamineria-en-risaralda-suena-un-gaviriatrujillo/

Garcés, Jhony (25 de septiembre de 2014) Quinchía: la multinacional Seafield, mucho tilín, tilín y nada de paletas. Tras la cola de la rata. Recuperado de https://www.traslacoladelarata.com/2014/09/25/quinchia-la-multinacional-seafield-mucho-tilin-tilin-y-nada-de-paletas/

Ossa, Leidy Johanna (10 de marzo de 2010). Se crea distrito minero en Risaralda. El Tiempo. Recuperado de http://www.eltiempo.com/archivo/documento/CMS-7399214

Vargas, Andrea (18 de octubre de 2015). Así planifican a Quinchía los candidatos. El Diario del Otún. Recuperado de http://www.eldiario.com.co/ seccion/POL \% C3 \% 8DTICA/as-planifican-a-quinch-a-los-candidatos1510. html

Documentos electrónicos

Ministerio del Interior (16 de septiembre de 2014). Acta de preconsulta en el marco de la consulta previa para el proyecto denominado "Títulos mineros de interés de la minera Seafield (hoy denominada Miraflores Compañía Minera) [...]" con la comunidad Karambá. Recuperado de http://www. mininterior.gov.co/sites/default/files/documentos/ConsultaPrevia/Protocolizaciones/acta_de_cierre_de_consulta_titulos_mineros_de_interes_de_ la_minera_seafield_S.A.S_proy643-01-03.pdf

Corporación Autónoma Regional de Risaralda (Carder) (2013). En Quinchía se instaló la mesa departamental "Minería Responsable y Sostenibilidad Ambiental”. Boletín Informativo. Recuperado de http://www.carder.gov.co/ app/webroot/index.php/cmsnews/webShow/496\#sthash.2vUJk6BT.dpuf

Corte Suprema de Justicia (29 de agosto de 2013). Acción de Tutela interpuesta en el 2013 por las comunidades indígenas de Quinchía. Ref. Exp. 11001-0203-000-2013-01900-00.

Integración de la Infraestructura Regional Suramericana (2013). Resumen de la cartera de proyectos IIRSA. Recuperado de http://www.IIRSA.org/ 
Información oficial de la Empresa Seafield Resource Ltd., 2016. Consultada en el 2016. Recuperado de http://www.sffresources.com/

Información oficial de la Empresa Batero Gold, 2016. Consultada en el 2016. Recuperado de http://www.baterogold.com/projects/batero-quinchia-projects

Proyecto Mesoamérica para la Integración y el Desarrollo (2013). Resumen de la cartera de proyectos Mesoamérica. Recuperado el 06 de enero de 2013, de http://www.proyectomesoamerica.org/ 